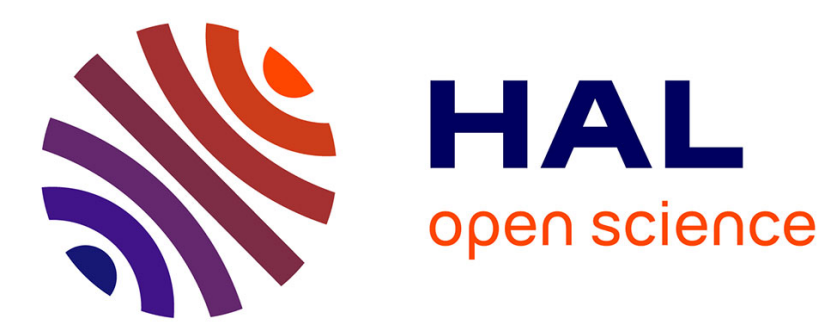

\title{
Modelling impact damage in marine composite panels
}

\author{
H.E. Johnson, L.A. Louca, S. Mouring, A.S. Fallah
}

\section{To cite this version:}

H.E. Johnson, L.A. Louca, S. Mouring, A.S. Fallah. Modelling impact damage in marine composite panels. International Journal of Impact Engineering, 2008, 36 (1), pp.25. 10.1016/j.ijimpeng.2008.01.013 . hal-00545294

\section{HAL Id: hal-00545294 \\ https://hal.science/hal-00545294}

Submitted on 10 Dec 2010

HAL is a multi-disciplinary open access archive for the deposit and dissemination of scientific research documents, whether they are published or not. The documents may come from teaching and research institutions in France or abroad, or from public or private research centers.
L'archive ouverte pluridisciplinaire HAL, est destinée au dépôt et à la diffusion de documents scientifiques de niveau recherche, publiés ou non, émanant des établissements d'enseignement et de recherche français ou étrangers, des laboratoires publics ou privés. 


\section{Accepted Manuscript}

Title: Modelling impact damage in marine composite panels

Authors: H.E. Johnson, L.A. Louca, S. Mouring, A.S. Fallah

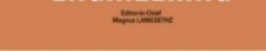

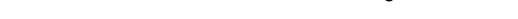

PII: $\quad$ S0734-743X(08)00073-0

DOI: $\quad$ 10.1016/j.jijimpeng.2008.01.013

Reference: IE 1579

To appear in: International Journal of Impact Engineering

Received Date: 8 September 2006

Revised Date: 18 January 2008

Accepted Date: 21 January 2008

Please cite this article as: Johnson HE, Louca LA, Mouring S, Fallah AS. Modelling impact damage in marine composite panels, International Journal of Impact Engineering (2008), doi: 10.1016/j.jimpeng.2008.01.013

This is a PDF file of an unedited manuscript that has been accepted for publication. As a service to our customers we are providing this early version of the manuscript. The manuscript will undergo copyediting, typesetting, and review of the resulting proof before it is published in its final form. Please note that during the production process errors may be discovered which could affect the content, and all legal disclaimers that apply to the journal pertain. 


\title{
Modelling impact damage in marine composite panels
}

\author{
H. E. Johnson ${ }^{\text {a }}$ L. A. Louca ${ }^{\text {a }}$ S. Mouring ${ }^{\text {, }}$ A. S. Fallah ${ }^{\mathrm{a}}$ \\ a Department of Civil \& Environmental Engineering, Imperial College London, SW7 2AZ, United Kingdom \\ b Department of Naval Architecture and Ocean Engineering, United States Naval Academy, Annapolis, MD 21402, \\ U.S.A
}

\begin{abstract}
In order to establish the survivability of a composite structure under a dynamic load, it is important to be able to predict the damage incurred and the effect of the contact force. The damage caused by low velocity impact is often hidden and for thicker plates the transverse stresses are significant in promoting delamination. In this study, woven vinyl-ester composite plates up to $1.37 \mathrm{~m}$ long are numerically modeled with a simple, gradually damaging threedimensional material model and the results are compared with full-scale tests. The model is based on damage mechanics principles using cyclic test data to obtain modulus reduction with damage. Delamination is modeled with a mixed-mode traction-separation law using cohesive elements. The non-linear elastic orthotropic material model for the woven plies is written in a VUMAT in Abaqus/Explicit and the effects of varying some of the modelling parameters are briefly discussed through the examination of the contact force.
\end{abstract}

Keywords: woven composites; impact; finite element; damage mechanics; delamination;

\section{Introduction}

Developments in the use of fibre composite materials for the construction of naval vessels have increased significantly over the last decade. This has been driven by the need for increased performance requirements in terms of stealth, payload, range, stability and at the same time, a reduction in costs both in terms of maintenance, operation and construction. Much experience in the use of composites in the marine environment has been obtained from the design of composite minesweepers which were designed using high stiffness requirements and not for the current vessels being planned. The stiffness of composites can be determined fairly accurately using finite element models and material properties from standard material characterisation tests. However, with more demanding requirements this has changed and the prediction of damage is something that is now required in order to satisfy higher performance demands. This is not as simple as determining elastic stiffness of the structure due to the complex damage modes that can occur in composites. This is particularly true under impact loading scenarios.

Commercial finite element (FE) codes are currently implemented to model impact of composite plates but most still lack effective constitutive models for laminates experiencing damage. Large-scale experimental data is also scarce in the public domain on many naval composites, particularly so with regards to dynamic data such as contact forcetime history, which according to Zhou and Greaves [1] is one way of revealing the dominant damage mechanisms, namely delamination and fibre failure.

The initiation of damage in composite materials is the point at which the stresses or strains in the material are large enough to incur some permanent deformation in the form of matrix cracking. Stress or strain based criteria have been the most common tools to model failure on a macro-scale but in a basic way, degrading the properties once only down to a residual value [2,3]. Currently however, continuum damage mechanics (CDM) is becoming increasingly popular and has yet to be introduced in many finite element packages for composite modelling. With reference to damage of composites, Ladeveze and LeDantec [4] and Chaboche [5] produced some of the earlier work in this area. The main limitations of a CDM models however, arise from the testing procedures and suitable experimental data is often difficult to generate.

A variety of constitutive models have been proposed for woven composites. Of particular interest in the field of CDM and impact modelling of woven composites is Iannucci's works. Iannucci et al. [6] modelled damage propagation of woven GFRP subjected to impact using shell elements. This was extended to solid elements in the 
work by Camanho et al. [7]. More recently the model was extended to include delamination using cohesive elements [2]. Matzenmiller et al [8] also developed an in-plane anisotropic damage mechanics model to model several damage modes excluding delamination. The model was tested against uniaxial tensile, compressive and simple shear tests. Other approaches to modelling woven composites includes that by Kollegal [9] who used an in-plane damage mechanics model to meshed unit cells of a plain weave composite under quasi-static loading.

Delamination is a major damage mode in thick composite plates subjected to low velocity impact. Although the use of resin-rich layer techniques has in the past provided good results $[10,11]$ its reliability is questionable [12] as they do not model the physical separation and ensuing contact condition of the delaminated layers. It is evident that to effectively model delamination and reduce the contact force, cohesive elements are an attractive option and have been popular for modelling delamination in small scale composites plates [13-16]. More recently and more specific to naval composites, Lemmen et al [17] proposed a damage mechanics based model using a damage initiation criterion based on Hashin's work [18] for quasi-static loading of a T-joint panel and modelling delamination with cohesive elements.

Although a large volume of much work has been carried out in modelling quasi-static fracture of aerospace composites, the investigation in the behaviour of marine composite plates under impact is not as well studied. Some work includes that by Zhou and Greaves [1] who carried out low velocity impact tests on thick GFRP laminates, producing high incident kinetic energy with the use of large masses, plotting the ratio of two impact force thresholds (delamination and final rupture) against delamination area as a way of analyzing the state of damage. On the other hand, Sierakowski and Chaturverdi [19] plotted the change in modulus with damage area using CAI (compression after impact) tests. Davies et al. [20] subjected even smaller thick circular polyester GFRP laminates to low velocity impact using a flat nosed impactor and examined the occurrence of the most dominant failure modes: delamination and fibre shear-out.

Impact kinetic energy, delamination area and depth of surface indent have previously been used as measures of damage of composites under impact. Work by Sutherland and Guedes Soares [21] however, highlights how the size and shape of the contact force provides a better reflection of the level of damage incurred by the composite. Sutherland et al produced some interesting work on the impact response of small circular plates for a range of diameter to thickness ratios. The plate behaviour was typified by damage progression in three stages: undelaminated (yet irreversibly absorbing energy); delaminated and fibre damage and used an energy balance approach to give correlation between impact force and incident energy.

The effect of strain rate for the impact velocities considered is debatable. Sutherland et al found that in-plane strain rate effects were significant when bending dominated (and therefore more so for thinner plates) but not so for the thicker plates or when considerable damage was created by the load. Strain rate tests for values of up to $1000 \mathrm{~s}^{-1}$ was carried out by the USNA (United States Naval Academy) investigating underwater explosions on a woven roving (WR) E-glass/Derakane 8084 vinyl ester manufactured by hand lay-up and the SCRIMP process. The report (which is unavailable in the public domain) identifies less significant changes in material strength and stiffness for strain rates of 100 to $1000 \mathrm{~s}^{-1}$ than for 0.1 to $100 \mathrm{~s}^{-1}$. Strain rate data for the same composite system but manufactured using hand-lay-up, resulted in poorer material consolidation than using the VARTM technique. Stress-strain tensile and compression tests carried out at a strain rate of $100 \mathrm{~s}^{-1}$ for this hand-layup produced lower strength values than for the VARTM composite tested quasi-statically. Prior to this, Smith and Murphy [22] already reported on the inconclusive and contradictory nature of strain rate data relating to woven composites. More recently, Heimbs et al. [23] carried out strain rate tests between $10 \mathrm{~s}^{-1}$ to $300 \mathrm{~s}^{-1}$ on WR glass/phenolic composites and found significant increases in strength of up to $88 \%$ in the weft direction compared to static ones for strain rates exceeding $50 \mathrm{~s}^{-1}$, compared to a smaller increase of only $33 \%$ in in-plane shear. The Young's modulus also appeared to increase only marginally.

Strain rate data on its own is of little use when a CDM model is involved. In order to obtain the degraded moduli for the gradually damaging material model, the cyclic tests would have to be carried out under dynamic strain rates, For rates up to $100 \mathrm{~s}^{-1}$, the USNA have an Instron Servo hydraulic machine capable of applying tensile loads to this rate, however it is not able to carry out cyclic tests at these high rates. The use of the Split Hopkinson bar for such tests is limited, as briefly described by Iannucci et al [6] who used inverse modelling to obtain the necessary parameters for his damage lag model. The exclusion of strain rate sensitivity in the present work can thus be justified primarily for the lack of robust test methods. Secondly, due to the conflicting test results. Thirdly, the impact velocities used in 
the present work are very low and the plates demonstrate a flexural response as opposed to a dilatational wave response seen with very short impact times. Dechaene et al [24] found that the threshold between low and high impact velocities can be defined in terms of the ratio of impact velocity and the speed of sound through the thickness of the composite. The transverse waves, responsible for material phase changes, should be considered for strain rates above $20 \mathrm{~s}^{-1}$, which on a whole are not being reached in the impact tests in the present work. Fourthly, given that many of the naval sections are still produced using hand-layup, the use of the superior VARTM material properties in the current material model has a compensatory effect for the lack of consideration of strain rate induced increase in stiffness and strength.

In this paper, WR E-glass/Derakane 8084 vinyl-ester composite plates up to $1.37 \mathrm{~m}$ long were tested under impact loading using energies of up to $7200 \mathrm{~J}$ and compared to finite element models in Abaqus/Explicit. A user-defined subroutine called a VUMAT was used to write the constitutive behaviour for a non-linear elastic damaging material model. Modelling the transverse behaviour of thick woven composite plates is important [25], and the plates are thus discretised with solid elements thereby allowing the required $3 \mathrm{~d}$ degradation of the woven ply material via a simple damage mechanics approach. Delamination between plies or groups of plies is also modeled using cohesive elements and a traction-separation law available in Abaqus/Explicit. Cyclic tests were carried out to obtain damage parameters and the FE models are validated against full-scale impact tests on GFRP panels. The material model serves to provide a relatively simple but effective method of modelling damage and material behavior without being wholly reliable on complex testing procedures.

\section{The finite element model}

\subsection{In-plane matrix and fibre damage}

Damage in the in-plane direction is dealt with using a simple strain based continuum damage model (CDM) applied at the plies. A ply in this study is a woven lamina with tows $90^{\circ}$ to each other. A test that produces stable crack growth is required to characterize the effect of damage propagation in composites. Unnotched coupon tensile tests used in the past produce unstable crack growth soon after the start of any damage but cyclic or fatigue loading is one method of obtaining stable crack growth by developing the damage very slowly. Work by Talreja [26] show that changes in moduli seen in fatigue testing of coupons can be used to quantify the damage incurred.

Previous work [26-28] shows that matrix damage occurs first followed by combined matrix and fibre damage until full failure. The in-plane CDM model can thus be regarded as consisting of four stages of material response:

1. Undamaged elastic stage

2. Damaging stage $1-$ matrix dominated

3. Damaging stage 2 - fibre and matrix dominated

4. Failed

There are several basic assumptions associated with this in-plane damage model, these are:

i. The term 'damage' is generally referred to as the proportion of damaged material and is manifest in the abated stiffness. This is not necessarily equivalent to volumetric crack ratio e.g. a material cross-section may be $80 \%$ saturated with cracks while the loss in stiffness not necessarily equal to $80 \%$ of the original stiffness. In this model, the term damage means the same as stiffness reduction. The stiffness reduction occurs as a result of the presence of numerous cracks within a unit volume of the material. In the FE analysis the reduced stiffness posterior to a certain criterion being met is represented by the stiffness at a damaged material point. This assumption implies that the crack size must be very small in relation to the volume associated with the material point, thus the cracks are not individually modeled (discrete crack model) but considered to be averaged and 'smeared' over the element volume (smeared crack model). The amount of damage can be expressed through the damage parameter $\mathrm{d}$.

ii. Keeping with the first and second laws of thermodynamics, the damage is irreversible and therefore the damage function is monotonically increasing i.e. $d\left(t^{n+1}\right)={ }_{t^{n} \leq t^{n+1}}^{\max }\left\{d\left(t^{n}\right)\right\}$. 
The condition states that the damage in the current time is dependent on the maximum attained damage during the loading history up to the current time. The expression is with reference to the time scale in the explicit FE analysis. The 'current time' is in fact the time at the end of the current time increment, which can be expressed as $\mathrm{t}^{\mathrm{n}+1}=\mathrm{t}^{\mathrm{n}}+$ $\mathrm{dt}$, where $\mathrm{n}$ is the number of the increment.

iii. The material is elastic damaging and therefore the strains comprise of elastic strains and damage strains only. Inelastic strains are caused by damage to the material (such as matrix cracking). In this model however, the constitutive behaviour is non-linear elastic. It is assumed that the interpolation functions of the finite element software give a good approximation of the strain at the integration point. It is also assumed that this strain includes the crack opening displacements smeared over the element. The damage is elastic so that when cracks have been formed/opened when the material is loaded then they close again when the load is removed. No permanent deformation is thus modeled. This 'damage strain' is achieved through a reduction in modulus which in turn results in larger strains.

\subsubsection{Initiation of matrix damage}

Damage initiation is assumed to occur when a crack is created in any direction in the material and is followed by damage propagation. Two damage initiation criteria were put to the test. The first was Hashin's $3 \mathrm{~d}$ stress criterion for transverse matrix crack initiation for tensile or compressive loading [18]. The FE analysis results were not satisfactory with this formulation since damage initiation was predicted very late on in the analyses. Also the tensile (bottom) side of the plate was always first to damage and continuing to do so predominantly more than the top of the plate and predicting over-extensive areas of damage.

The second damage initiation criterion and the most successful is an equivalent strain criterion suggested by Williams et al. [29] and successfully used for impact analyses of composite plates. The version shown in Equation (1) includes the through-thickness strain component for application to a $3 \mathrm{~d}$ model. This criterion was used in the present study to predict the start of material degradation for both the in-plane and through the thickness directions. This global initiation criterion was chosen following poor results using separate criteria for transverse damage initiation such as Brewer and Legace's delamination criterion [30].

- Equivalent strain function, a 3d version of that used by Williams et al. [29]

$$
\mathrm{F}_{\mathrm{ini}}=\sqrt{\left(\frac{\varepsilon_{11}}{\mathrm{~K}}\right)^{2}-\left(\frac{\varepsilon_{11}}{\mathrm{~K}}\right)\left(\frac{\varepsilon_{22}}{\mathrm{~L}}\right)+\left(\frac{\varepsilon_{22}}{\mathrm{~L}}\right)^{2}+\left(\frac{\gamma_{12}}{\mathrm{~S}}\right)^{2}+\left(\frac{\gamma_{23}}{\mathrm{~T}}\right)^{2}+\left(\frac{\gamma_{31}}{\mathrm{U}}\right)^{2}+\left(\frac{\varepsilon_{33}}{\mathrm{~V}}\right)^{2}} \geq 1
$$

Where K, L, V, S, T and U are the strains to failure of the ply in the in-plane 1-direction, the in-plane 2-direction, out-of-plane 3-direction, the in-plane shear direction (12), and the two transverse shear directions 23 and 13 respectively using standard tensile and compressive tests.

\subsubsection{Matrix and fibre damage propagation}

Once damage has initiated with the equivalent strain criterion, the material degrades and the elastic properties of the virgin material, shown in

\begin{tabular}{|c|c|c|c|c|c|c|c|c|c|}
\hline $\mathrm{E}_{11 \mathrm{~T}}$ & $\mathrm{E}_{11 \mathrm{C}}$ & $\mathrm{E}_{22 \mathrm{~T}}$ & $\mathrm{E}_{11 \mathrm{C}}$ & $\mathrm{E}_{12}$ & $\mathrm{E}_{13}$ & $\mathrm{E}_{23}$ & $\mathrm{E}_{33 \mathrm{~T}}$ & $\mathrm{E}_{33 \mathrm{C}}$ & $\mathrm{v}_{12}$ \\
\hline 24.139 & 23.37 & 24.139 & 23.37 & 8.273 & 3.586 & 3.586 & $\begin{array}{c}16.89 \\
\text { (range }\end{array}$ & $\begin{array}{c}8.1 \\
\text { (range }\end{array}$ & 0.14 \\
& & & & & & & & 6.18 to \\
& & & & & & & & \\
& & & & & & & & \\
& & & & & & & & \\
& & & & & & & \\
\end{tabular}

Table 1, are diminished until failure which must be accounted for in the constitutive equations. The mean value of the energy density for a damaged material will therefore be different to that for an intact material. The stress acting over the undamaged portion of the material is known as the effective stress, which can be defined with the 
relationship in Equation (2) where $\mathrm{d}$ is the damage parameter and $\sigma$ is the stress over the original undamaged material cross-section.

$\bar{\sigma}=\frac{\sigma}{(1-d)}$

Each damage phase can be characterized by one or more of these variables. These variables are used to degrade the material properties and can vary from 0 (no damage) to 1 but a $10 \%$ residual stiffness is maintained so $\mathrm{d}$ only reaches a maximum of 0.9 . This percentage residual was chosen as a result of in-house testing at DSTL suggesting $5-10 \%$ and previous work [31] supporting $10 \%$. Iannucci [2] also justifies this residual by approximating the residual strength of the composite to the strength of the resin, which is only $16.5 \mathrm{MPa}$ in tension, compared to the composite strength properties shown in

\begin{tabular}{|c|c|c|c|c|c|c|}
\hline $\mathrm{S} 11_{\mathrm{T}}$ (warp) & $\mathrm{S} 22_{\mathrm{T}}($ weft) & $\mathrm{S} 11_{\mathrm{c}}=\mathrm{S} 22_{\mathrm{c}}$ & $\mathrm{S} 13$ & $\mathrm{~S} 23$ & $\mathrm{~S} 33_{\mathrm{T}}$ & $\mathrm{S} 33_{\mathrm{C}}$ \\
\hline 330.328 & 298.6 & 329.6 & 51.6 & 51.6 & $\begin{array}{c}30.5 \\
\text { (range 19.37 } \\
\text { to 41.71) }\end{array}$ & $\begin{array}{c}570 \\
\text { (range 520 } \\
\text { to 620) }\end{array}$ \\
\hline
\end{tabular}

Table 2. The effect of the fibre presence will add to the strength but this is dependent on the fibre orientation angle which is not readily quantifiable. In addition to the above, a residual stiffness also helps to avoid numerical problems.

Based on assumption $i$ early on, the original intact moduli $\mathrm{E}_{0}$ are therefore degraded as shown with the generalized Equation (3).

$\mathrm{E}=(1-\mathrm{d}) \mathrm{E}_{0}$

The energy absorbed by the material per unit volume is a function of the material's elastic properties and the stresses in the material. Thus the mean value of the strain energy density of the damaged material can be expressed as shown with Equation (4) which includes damage under compression.

$E_{d}=\frac{1}{2}\left[\frac{\sigma_{11}^{2}}{E_{1}^{0}\left(1-d_{1}\right)}-2 \frac{v_{12}^{0}}{E_{1}^{0}} \sigma_{11} \sigma_{22}+\frac{\sigma_{22}^{2}}{E_{2}^{0}\left(1-d_{2}\right)}+\frac{\sigma_{12}^{2}}{G_{12}^{0}\left(1-d_{3}\right)}\right]$

The internal damage variables are associated with the thermodynamic forces, $\mathrm{Y}_{\mathrm{i}}$, which can also be referred to as the energy density release rates. They represent the change in energy density due to a change in the material microstructure resulting from damage. The evolution of damage in each material direction can be represented with the damage parameters that can be expressed in terms of one or more damage energy release rate variables, $\mathrm{Y}_{\mathrm{i}}$. For example, matrix cracking in one of the in-plane fibre directions, may be attributed to loading not only in this material direction but from in-plane shear stress also; as the type of damage produced is similar between normal inplane tension and in-plane shear. Therefore in theory, a combination of stresses could be responsible for the damage incurred in each one of the material directions, and the damage parameter could, for a plane stress model, be a function of all of three energy density release rates, as shown with equations (5). This is in effect used to model coupling of different damage modes but if coupling is excluded then the relationships reduce to Equations (6).

$$
\begin{aligned}
& d_{1}=f_{1}\left(Y_{1}, Y_{2}, Y_{3}\right) \quad d_{2}=f_{2}\left(Y_{1}, Y_{2}, Y_{3}\right), d_{3}=f_{3}\left(Y_{1}, Y_{2}, Y_{3}\right) \\
& d_{1}=f_{1}\left(Y_{1}\right) \quad d_{2}=f_{2}\left(Y_{2}\right), d_{3}=f_{3}\left(Y_{3}\right) \\
& d_{1}=f_{1}\left(\varepsilon_{1}\right) \quad d_{2}=f_{2}\left(\varepsilon_{2}\right), d_{3}=f_{3}=f\left(d_{1}, d_{2}\right)=f_{3}\left(\varepsilon_{1}, \varepsilon_{2}\right)
\end{aligned}
$$


The present work however, the functions describing the damage variables were written in terms of the strains. This was chosen because the damage evolution from cyclic tests could only be obtained as far as the initiation of fibre damage. Tests to derive the energy density during both matrix and fibre damage evolution could not be carried out. Although cracks in the two orthogonal planes can also be created by the in-plane shear stress, here the shear damage variable $\mathrm{d}_{3}$, which controls shear damage only, is not obtained directly from cyclic shear tests but is calculated as a function of the normal in-plane damage modes.

In-plane damage propagation can be described with a bilinear model, see Figure 1, based on the four stages of damage described earlier. The value of each variable at each moment in time during the loading phase depends on a step function $F$. It is made up of the damage development functions $F_{\text {ini }} F_{m}$ and $F_{f}$ as shown in Equation (8). The function for damage initiation i.e. the start of damaging stage 1 , is $F_{\text {ini }}$, which is equal to Equation (1) described earlier. Thus when matrix damage is predicted then $\mathrm{F}_{\mathrm{i}}=1$ and $\mathrm{F}=1=\mathrm{F}_{\mathrm{I}}$.

The function that predicts the start of damaging stage 2 is $\mathrm{F}_{\mathrm{m}}$. When fibre damage initiates $\mathrm{F}_{\mathrm{m}}=1$ then $\mathrm{F}=2=\mathrm{F}_{\mathrm{II}}$, see

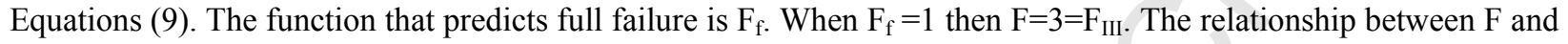
$\mathrm{d}$ can be described with Equations (9), where $d_{m}$ represents the portion of damage attributed to stage 1 (matrix damage only) and $\mathrm{d}_{\mathrm{f}}$ to stage 2 damage.

$\mathrm{F}=\mathrm{F}_{\mathrm{i}}+\mathrm{F}_{\mathrm{m}}+\mathrm{F}_{\mathrm{f}}$

Step function

$\mathrm{d}=\left\{\begin{array}{lll}0 & =\mathrm{d}_{\mathrm{m}} & \Leftarrow 0<\mathrm{F} \leq \mathrm{F}_{\mathrm{I}} \\ (\mathrm{F}-1) \mathrm{d}_{\mathrm{II}} & =\mathrm{d}_{\mathrm{m}} & \Leftarrow \mathrm{F}_{\mathrm{I}}<\mathrm{F} \leq \mathrm{F}_{\mathrm{II}} \\ \mathrm{d}_{\mathrm{II}}+\left(0.9-\mathrm{d}_{\mathrm{II}}\right)(\mathrm{F}-2) & =\mathrm{d}_{\mathrm{m}}+\mathrm{d}_{\mathrm{f}} & \Leftarrow \mathrm{F}_{\mathrm{II}}<\mathrm{F} \leq \mathrm{F}_{\mathrm{III}} \\ 0.9 & \mathrm{~d}_{\mathrm{m}}+\mathrm{d}_{\mathrm{f}} & \Leftarrow \mathrm{F}>\mathrm{F}_{\mathrm{III}}\end{array}\right.$

The orthotropic nature of the WR composite requires that the in-plane moduli are reduced using individual functions. The damage variables for matrix and fibre damage responsible for degrading each of the 11 (warp), 22 (weft) and 12 (shear) directions are denoted by $\mathrm{d}_{1}, \mathrm{~d}_{2}, \mathrm{~d}_{3}$ respectively. The variables $\mathrm{d}_{1}$ and $\mathrm{d}_{2}$ are applied to the warp and weft directions respectfully and are shown in Equations (10) in terms of the variables at each damage stage $\mathrm{d}_{\mathrm{im}}$ and $\mathrm{d}_{\mathrm{if}}$. The matrix damage parameter is in the range of $\mathrm{d}_{\mathrm{I}}<\mathrm{d}<\mathrm{d}_{\text {II }}$ where $\mathrm{dI}$, dII and dIII represent the damage parameters at the end of stages I, II and III, respectively, and the damage function for matrix damage $\mathrm{F}_{\mathrm{m}}$ is in the range of $\mathrm{F}_{\mathrm{I}}<\mathrm{F}_{\mathrm{m}}<\mathrm{F}_{\mathrm{II}}$.

$\mathrm{d}_{1}=\mathrm{d}_{1 \mathrm{~m}}+\mathrm{d}_{1 \mathrm{f}}$

$\mathrm{d}_{2}=\mathrm{d}_{2 \mathrm{~m}}+\mathrm{d}_{2 \mathrm{f}}$

The damage parameters can be further split into 'tension' and 'compression', in other words: $d_{1 T}, d_{2 T}$ and $d_{1 C}, d_{2 C}$ respectfully. The individual original intact moduli, $\mathrm{E}_{\mathrm{ij}}^{0}$ in tension and compression are therefore degraded as shown with Equations (11). The stiffness loss is thus given by $\mathrm{E}_{\mathrm{ij}}^{0} \mathrm{~d}_{\mathrm{i}}$. A schematic of the relationship between $\mathrm{d}$ and $\mathrm{E}$ is shown in Figure 2.

$$
\begin{aligned}
& \mathrm{E}_{11 \mathrm{~T}}=\mathrm{E}_{11 \mathrm{~T}}^{0}\left(1-\mathrm{d}_{1 \mathrm{~T}}\right) \\
& \mathrm{E}_{11 \mathrm{C}}=\mathrm{E}_{11 \mathrm{C}}^{0}\left(1-\mathrm{d}_{1 \mathrm{C}}\right) \\
& \mathrm{E}_{22 \mathrm{~T}}=\mathrm{E}_{22 \mathrm{~T}}^{0}\left(1-\mathrm{d}_{2 \mathrm{C}}\right) \\
& \mathrm{E}_{22 \mathrm{C}}=\mathrm{E}_{22 \mathrm{C}}^{0}\left(1-\mathrm{d}_{2 \mathrm{C}}\right)
\end{aligned}
$$


The tensile and compressive moduli are only available for one of the orthogonal in-plane directions, therefore in the present work it is approximated that $\mathrm{E}_{22}=\mathrm{E}_{11}$, as shown in

\begin{tabular}{|c|c|c|c|c|c|c|c|c|c|}
\hline $\mathrm{E}_{11 \mathrm{~T}}$ & $\mathrm{E}_{11 \mathrm{C}}$ & $\mathrm{E}_{22 \mathrm{~T}}$ & $\mathrm{E}_{11 \mathrm{C}}$ & $\mathrm{E}_{12}$ & $\mathrm{E}_{13}$ & $\mathrm{E}_{23}$ & $\mathrm{E}_{33 \mathrm{~T}}$ & $\mathrm{E}_{33 \mathrm{C}}$ & $\mathrm{v}_{12}$ \\
\hline 24.139 & 23.37 & 24.139 & 23.37 & 8.273 & 3.586 & 3.586 & $\begin{array}{c}16.89 \\
\text { (range }\end{array}$ & $\begin{array}{c}8.1 \\
\text { (range }\end{array}$ & 0.14 \\
& & & & & & & & \\
& & & & & & & & \\
& & & & & & & & \\
& & & & & & & & \\
& & & & & & & \\
\end{tabular}

Table 1.

The in-plane shear damage parameter $d_{3}$, can be given directly using Williams et al. [29] damage coupling criterion shown in Equation (12), omitting the need to carry out cyclic shear tests.

$d_{3}=\sqrt{d_{1}^{2}+d_{2}^{2}-d_{1} d_{2}}$

Similar degradation rules can be applied to the Poisson's ratios. Poisson's effect from the orthogonal direction, $\mathrm{v}_{21}$, for example, is affected by the damage in the 22 direction and not from cracks in the 11 direction. The symmetry of the compliance tensor applies to both the damaged and undamaged material however, thus the following relationship applies, where the superscript ' $d$ ' refers to the damaged variable:

$$
\begin{aligned}
& \frac{v_{12}}{E_{11}}=\frac{v_{21}}{E_{22}} \\
& \frac{v_{12}^{d}}{E_{11}^{d}}=\frac{v_{21}^{d}}{E_{22}^{d}}
\end{aligned}
$$

Hence Poisson's ratios can be degraded as shown with Equations (14).

$$
\begin{aligned}
& v_{12}=v_{12}^{0}\left(1-d_{1}\right) \\
& v_{21}=v_{21}^{0}\left(1-d_{2}\right)
\end{aligned}
$$

The values assigned to $d_{I I}$ for the warp and weft directions in tension and compression (i.e. $d_{I I(1) \mathrm{T}}, d_{I I(1) C}, d_{I I(2) T}$ and $\left.\mathrm{d}_{\mathrm{II}(2) \mathrm{C}}\right)$ are given in

\begin{tabular}{|l|l|l|l|}
\hline Cyclic testing & $\boldsymbol{\varepsilon}_{\mathbf{f}}$ & $\boldsymbol{\varepsilon}_{\max }$ & $\mathbf{d}_{\text {II }}$ \\
\hline Warp, tensile & 0.0225 & 0.04 (Williams et al.) & 0.17 \\
\hline Warp, compressive & -0.015 & -0.04 & 0.035 \\
\hline Weft, tensile & 0.0208 & 0.04 & 0.23 \\
\hline Weft, compressive & -0.015 & -0.04 & 0.027 \\
\hline
\end{tabular}

Table and were obtained from the cyclic tests as described in the experimental section. The damage parameter $\mathrm{d}_{\text {III }}$ is assigned a fixed value of 0.9 to maintain the $10 \%$ residual stiffness, as explained above.

\section{Matrix damage development function, $F_{m}$}

Matrix damage development (stage 1 damage) is predicted using the general linear strain function Equation (15); where $\varepsilon_{0}$ is the strain at which matrix damage initiates, $\varepsilon$ is the actual instantaneous strain calculated in the analysis and $\varepsilon_{\mathrm{f}}$ is the strain at which fibre damage initiates. The strain thresholds used in these damage development functions were obtained from tensile cyclic tests for each orthogonal in-plane direction for both tension ' $T$ ' and 
compression ' $\mathrm{C}$ '. In other words, functions $\mathrm{F}_{\mathrm{m} 1 \mathrm{~T}}, \mathrm{~F}_{\mathrm{m} 1 \mathrm{C}}$ and $\mathrm{F}_{\mathrm{m} 2 \mathrm{~T}}, \mathrm{~F}_{\mathrm{m} 2 \mathrm{C}}$ were obtained, representing the damaging phase 1 for in-plane directions 11 and 22 , respectfully.

$\varepsilon_{\mathrm{flT}}=$ strain at the start of fibre damage in the warp direction under a tensile load.

$\varepsilon_{\mathrm{f} 2 \mathrm{~T}}=$ strain at the start of fibre damage in the weft direction under a tensile load.

$\varepsilon_{\mathrm{flC}}=$ strain at the start of fibre damage in the warp direction under a compressive load

$\varepsilon_{\mathrm{f} 2 \mathrm{C}}=$ strain at the start of fibre damage in the weft direction under a compressive load.

$$
\mathrm{F}_{\mathrm{m}}=\frac{\varepsilon_{\mathrm{f}}<\varepsilon-\varepsilon_{0}>}{\varepsilon\left(\varepsilon_{\mathrm{f}}-\varepsilon_{0}\right)}
$$

The function $<x>$ (Macaulay brackets) means $x \mathrm{H}(x)$ where $\mathrm{H}$ is the Heaviside step function thus the formulation of Equation (15) suggests that damage cannot initiate until $\varepsilon_{0}$ has been reached. This strain is dictated by the damage initiation function. Therefore the strain in the warp and weft directions, $\varepsilon_{01}$ and $\varepsilon_{02}$, when $\mathrm{F}_{\text {ini }}=1$ are recorded during the FE analysis and used in the above expression. Hence their values are not fixed.

\section{Fibre damage development function, $F_{f}$}

The potential function is based on the strain to failure of the fibre, $\varepsilon_{\max }$, as shown with Equation (16), calculated for each of the two principal in-plane (fibre) directions

$$
\mathrm{F}_{\mathrm{f}}=\frac{\varepsilon}{\varepsilon_{\max }}
$$

The strain at rupture, parameter $\varepsilon_{\max }$, is not easy to estimate analytically and requires test data. As one would expect, the strain to failure of the undamaged composite material is found to be lower than that of the damaged material in the softening zone, as shown by Kongshavn and Poursartip [32] and their work on carbon fibre/epoxy systems. This work involved growing damage in a stable manner using a compact tension specimen then carrying out tensile tests to failure using material from the damaged portion of the specimen, demonstrating rupture strains of $3-4 \%$. Tensile tests to failure for the undamaged material on the other hand, gave rupture strains of about $1.5 \%$. Williams et al. [29] used a strain to rupture value of 0.04 in their model, giving reference to Kongshavn and Poursartip's experimental work [32]. Thus, due to unavailable experimental data for fibre failure for the woven Eglass/vinyl ester in the present work, we use the strain value of 0.04 to depict full fibre failure and therefore full material failure in the warp and weft directions in tension and compression, see

\begin{tabular}{|l|l|l|l|}
\hline Cyclic testing & $\boldsymbol{\varepsilon}_{\mathbf{f}}$ & $\boldsymbol{\varepsilon}_{\max }$ & $\mathbf{d}_{\text {II }}$ \\
\hline Warp, tensile & 0.0225 & 0.04 (Williams et al.) & 0.17 \\
\hline Warp, compressive & -0.015 & -0.04 & 0.035 \\
\hline Weft, tensile & 0.0208 & 0.04 & 0.23 \\
\hline Weft, compressive & -0.015 & -0.04 & 0.027 \\
\hline
\end{tabular}

Table . In reality however, this strain may be larger for this woven roving and different depending on the direction of the loading. It was found however, that changes to this value of up to $20 \%$ made little difference to the contact force and out-of-plane displacements.

\subsection{Transverse damage}

In terms of transverse damage, delamination and ply-shear out are two of the principal damage mechanisms [1]. In a woven ply, intra-bundle and inter-bundle in-plane cracks can develop, the latter often resulting in inter-bundle delamination [33-36]. This is not the same as inter-ply delamination which has the effect of reducing the inter-ply stiffness but has no effect on the actual properties of the woven ply material. Thus in the present work a transverse intra-ply degradation model is applied in addition to the cohesive elements in between the plies.

\subsubsection{Transverse intra-ply degradation of the woven ply (TIP model)}


Here the transverse properties of the ply material are degraded using stress based criteria. The variation in the normal transverse modulus obtained from standard tensile tests was significant, with values ranging from 6.98 to $22.68 \mathrm{kN} / \mathrm{mm}^{2}$ and for simplicity the average of the most abundant values was used in the analyses. Strain based criteria would have been preferred, as with the in-plane CDM model, however only failure stress data was available for this particular composite. Owing to computational reasons, not every ply in a thick plate FE model can be analysed for delamination. Thus in these cases, one solid element through the thickness can represent two or more plies as an orthotropic continuum. It was found for these cases in particular, that modelling the degradation of the transverse properties at the ply/plies is very important to effectively represent the behaviour of the plate. A CDM model would have been preferred over simple stress criteria, however there are no standard out-of-plane tension or compression tests. Although a modified ASTM C-297 test provides adequate results, maintaining load train and specimen alignment is a difficulty associated with this method and the procedure would have to be significantly modified for cyclic testing.

The through thickness damage is assumed to consist of the following:

1. Undamaged elastic stage

2. Damaging stage - matrix cracking

3. Failed

The function for damage initiation is $F_{\text {ini }}$ is a global criterion, the same one used for initiating in-plane damage. The damaging and failed stage is defined by a maximum stress criterion, as described later.

Damage initiation is defined with the equivalent strain criterion. The transverse moduli of the solid elements are gradually reduced to a residual of $10 \%$ of their original value using the maximum stress criterion in Equation (17). The damage variables $\mathrm{d}_{4}, \mathrm{~d}_{5}$ and $\mathrm{d}_{6}$ are applied to the transverse shear 13, 23 and normal 33 directions, respectfully. The moduli are degraded using similar expressions to Equation (11). The difference between the compressive and tensile behaviour of the material is incorporated using the relevant ultimate stress values from standard transverse compressive and tensile tests.

$$
d=0.9\left(\frac{\sigma^{\max }-\sigma}{\sigma^{\max }}\right)
$$

\subsubsection{Delamination (inter-ply degradation)}

Delamination is a very severe damage mode in thick composites and has been observed extensively in shock loading tests. Delamination is also the predominant damage mechanism observed in impact tests of thick plates, preceded by matrix cracking. A cohesive element was implemented in the finite element (FE) models to improve the delamination prediction over stressed based criteria. Cohesive elements allow displacement discontinuities associated with cracks to be explicitly represented. These elements relate the displacement discontinuity across a crack to tractions that act across the crack which may be sustained by fibrils in cracked regions, bridging fibers, friction and other crack bridging mechanisms. Resin rich regions naturally exist between interfaces of each ply in a laminate and are known to promote delamination. In the models adopted, the resin rich regions were approximately $15 \%$ of the ply thickness.

Failure of the cohesive elements is initiated by a mixed-mode quadratic stress based criterion involving the normal and two shear stress components, see Figure 3. This implies that damage will most likely initiate at a stress that is smaller than the maximum stress for failure for the individual mode. A linear traction separation law is assumed to occur prior to damage.

The maximum attained value during the loading history of equivalent mixed mode displacement, $\overline{\mathrm{u}}_{\mathrm{m}}$, is used to detect the damage at the interface. The initiation of delamination damage is determined when a maximum nominal stress criterion, as shown in Equation (18), is equal to one. This occurs at mixed mode stress values of $\tau_{\mathrm{i}}=\tau_{\mathrm{i}}^{\max }$, 
where $\mathrm{i}=\mathrm{n}, \mathrm{s}, \mathrm{t}$, represents each of the three modes of delamination. Where Macaulay brackets are present indicates positive (tensile) stresses only and is therefore only relevant to the normal stress $\tau_{n}$. It is assumed that the mode I stress does not contribute towards delamination damage when this stress is compressive and therefore under this loading mode I behavior is excluded from the equation. $\mathrm{T}_{i}^{\max }$ in the equation, also shown in Figure 3 is the maximum stress for the pure modes (i.e. when no other mode is acting).

$$
\left(\frac{\left\langle\tau_{\mathrm{n}}^{\max }\right\rangle}{\mathrm{T}_{\mathrm{n}}^{\max }}\right)^{2}+\left(\frac{\tau_{\mathrm{s}}^{\max }}{\mathrm{T}_{\mathrm{s}}^{\max }}\right)^{2}+\left(\frac{\tau_{\mathrm{t}}^{\max }}{\mathrm{T}_{\mathrm{t}}^{\max }}\right)^{2}=1
$$

The quadratic stress criterion can also be written in terms of the displacements, Equation (19) by substituting the maximum stresses with the product of the penalty stiffness and the initiation strain.

$$
\left(\frac{\left\langle\mathrm{u}_{\mathrm{n}}^{0}\right\rangle}{\mathrm{U}_{\mathrm{n}}^{0}}\right)^{2}+\left(\frac{\mathrm{u}_{\mathrm{s}}^{0}}{\mathrm{U}_{\mathrm{s}}^{0}}\right)^{2}+\left(\frac{\mathrm{u}_{\mathrm{t}}^{0}}{\mathrm{U}_{\mathrm{t}}^{0}}\right)^{2}=1
$$

Once the damage initiation criteria is reached, the traction displacement is degraded linearly. The softening behavior can be either linear or exponential in Abaqus and for validation of a simpler model, a linear case was chosen. The area under the traction displacement curve, or the energy dissipated at crack propagation is equal to the fracture toughness for the particular fracture mode. A quadratic power law damage evolution criteria is adopted which controls the damage evolution. This defines the dependence of the fracture energy on the relative mode-mixity, Equation (20). The power indice defines the shape of the failure locus and is typically equal to one or two. There is still discrepancy as to which power indice should be used or if indeed the power law criterion is adequate for certain composites or not and opinions are varied [7,37]. However, according to Camanho [7] there is no reliable mixed mode loading criteria for delamination propagation that involves mode III because of the lack of adequate mixedmode tests that includes mode III activity.

$$
f(G)=\left(\frac{G_{n}}{G_{n C}}\right)^{\alpha}+\left(\frac{G_{t}}{G_{t C}}\right)^{\alpha}+\left(\frac{G_{s}}{G_{s C}}\right)^{\alpha}, \quad \alpha=2
$$

The small plates were modeled with cohesive elements at 4 and 8 inter-laminar regions. The largel plates were modeled with 7 cohesive layers and large 2 plates with 9 cohesive layers, each solid element therefore representing 5 plies for the latter case. With regards to delamination, the study firstly evaluates whether delamination can be adequately modeled with the full number of inter-ply regions using a cohesive zone model. Secondly, if modelling half the inter-ply regions still provides a reasonable indication as to the location and approximate size of the largest and smallest delaminated regions.

\section{Strain rate effect}

Strain rate effect on composites has been studied by researchers at different levels numerically and analytically as well as experimentally. For instance, Mamalis et al. [38] studied the crushing response and crashworthiness characteristics of thin walled CFRP tubes experimentally under impact loading and compared the maximum static and dynamic capacities. They observed the brittle manner in which the plate collapses under compressive loading for two unstable cases of local tube buckling and mid length collapse mode. They concluded the possibility of an increase in the energy absorption capacity only when localised damage in the impact zone (stable failure) occurred. However, this mode of failure only occurred in $22 \%$ of the test specimens and the majority failed in one of the unstable failure modes and thus high strain rate did not contribute to energy absorption capacity. They showed the maximum compressive strength and energy absorption capacity are positively affected as strain rate increases, 
however; this positive contribution was not quantified. In an analytical study by Wang et al. [39] to assess strain rate sensitivity of unidirectional composite laminates spring-dashpot models similar to those of rheological Kelvin-Voigt model of viscoelasticity were used and the unidirectional ply was simplified as a coated fibre bundle. They showed the higher sensitivity of GFRP plies to high strain rates than CFRP plies. They showed that the increase in load capacity due to strain rate is an almost linear function of strain rate with parameters extracted from tests. In a numerical study on the nonlinear transient response of rate dependent composite laminated plates Zhu et al. [40] showed significant nonlinearity in stress-strain behaviour in the directions perpendicular to fibre direction (matrix dominated directions). They reported an increase in the strength in fibre direction due to strain rate sensitive behaviour which is difficult to quantify. In a statistical model and experimental study by Xia et al. [41] on glass fibres it was shown that dynamic strength of glass fibres obeys the Weibull distribution with two rate-independent parameters. The two independent parameters are those of stress-strain curve shape and unloading damage parameter. As such, the shape of loading and softening parts on the monotonic strain-based stress-strain curves as well as the unloading damage curves would be similar at all strain rates. This conclusion is experimentally verified for glass fibres only and is suggested to be the same for other fibre types with different numerical values for these parameters. Shah Khan et al. [42] studied woven GRP plates in in-plane warp and weft loading directions. They concluded that the strength and modulus varied similarly with strain rate when the loading was in these directions. They observed that the in-plane elastic moduli and strength first increased with strain rate and then decreased markedly at higher strain rates. The increase was monotonic when strain rates were in the range of $10^{-3}-10 / \mathrm{s}$ and reached $20 \%$. Ochola et al. [43] conducted compressive tests on CFRP and GFRP laminate specimens in the strain rate range of $10^{-3}-450 / \mathrm{s}$. They concluded the increase in the strength of GFRP laminate with increasing strain rate and the decrease in strain to failure for both materials. More recently Iannucci and Ankersen [44] discussed the results of tests conducted on unidirectional and woven CFRP laminas and concluded high rate dependence of matrix dominated modes and almost independence of fire dominated modes for this type of composite.

Form the studies conducted by researchers and the abundance of literature available on this topic it can be concluded that strain rate effects cannot be conclusively commented on quantitatively. The results are limited to particular types of fibre and matrix and to a particular level and formulation. As such, they are sometimes even contradictory. As a general statement it can be expected that the rate dependence has a positive or zero contribution on load and energy absorption capacities which depends on fibre and matrix types, fibre content, stacking sequence and production method. Due to these intricacies and uncertainties strain rate sensitivity of GRP as suggested by the literature is not considered in the present study. The type of strain rates encountered in the FE analyses is bounded to 20/s (due to relatively low impact velocities). From the available literature the material modulus and strength can increase by up to $20 \%$ in this range which is judged to be compensated by the supremacy of VARTM method over hand lay-up.

\section{Mesh constraints}

The contact algorithm option of finite sliding for contact pairs was chosen for the impact analyses in Abaqus/Explicit because it is a more robust algorithm over small sliding, reflected largely in the far lesser dependence on the mesh density. The tup was discretised with an element size that was fine enough to minimize any sharp corners but slightly larger than the plate elements. Also the coarseness of the mesh becomes increasingly important with increase in the number of cohesive layers therefore a fine mesh is more desirable. The length of the cohesive zone was used to select an appropriate mesh size. Hilleborg [45] was the first to develop the FE interface cracking model for delamination in concrete, who proposed the relationship shown in Equation (21) with $\mathrm{n}$ equal to 1. The analysis names for the small plate tests are labeled according to test number, impact energy and tup size used.

$\mathrm{L}_{\mathrm{c}}=\frac{\mathrm{nE}_{\mathrm{c}} \mathrm{G}_{\mathrm{c}}}{\sigma_{\max }^{2}}$

The element length in the cohesive zone can thus be simply defined as shown in Equation (22), where $\mathrm{N}$ is the number of elements. The exact number of elements required in the cohesive zone is still being debated however. Some researchers have proposed more than 10 elements, others 2 to 5 [46], whereas Camanho and Davila [7] believe 3 elements is adequate enough, based on a parametric study on a DCB specimen. 


$$
\mathrm{L}_{\mathrm{e}}=\frac{\mathrm{L}_{\mathrm{c}}}{\mathrm{N}}
$$

Based on Hilleborg's expression and the material properties for the woven roving vinyl-ester composite, and the average mode I critical fracture energy of $596 \mathrm{~J} / \mathrm{m}^{2}$ and $806 \mathrm{~J} / \mathrm{m}^{2}, \mathrm{~L}_{\mathrm{c}}$ is calculated as $9.7 \mathrm{~mm}$. The structures considered in the present study are big compared to a DCB specimen, and more than 3 elements within the cohesive zone would be unwise in terms of numerical running times, even in Explicit. Therefore based on this number, the element length applied was no larger than $3.2 \mathrm{~mm}$. The small plates were also tested with a finer mesh of $1.6 \mathrm{~mm}$.

\section{Experimental Procedures \\ 3.1. Impact testing}

Three different plate sizes were subjected to impact tests. The plates were fabricated at the Naval Surface Warfare Center (NSWC), Carderock Divison using a proprietary 24 ounce woven roving E-glass/Derakane 8084 vinyl-ester manufactured with a vacuum assisted resin transfer moulding (VARTM) process producing typical volume fractions of $68-70 \%$. Woven roving reinforcements consist of bundles of continuous strands in a plain weave pattern with more material in the direction of the warp.

The smallest plates, of size $0.2286 \times 0.1778 \times 0.00635 \mathrm{~m}^{3}\left(9 \times 7 \times 0.25 \mathrm{in}^{3}\right)$ and 9 woven layers, were simply supported and impact tested using an Instron-Dynatup Model 9250HV (High Velocity) with Impulse Control and Data System. A photodiode was used to determine the velocity of the impact or just before impact. The panels were also illuminated by high-powered work lights in order for effective visualization of the target area. Three different hemispherical tup diameters were used to impact the small plates: a $12.7 \mathrm{~mm}(0.5 \mathrm{inch})$, a $25.4 \mathrm{~mm}(1 \mathrm{inch})$ and a $38 \mathrm{~mm}$ (1.5inch). The second largest plates of size $1.07315 \times 0.76835 \times 0.019 \mathrm{~m}^{3}\left(42.2 \times 30.2 \times 0.75 \mathrm{in}^{3}\right)$ (large 1$)$ were impact tested using a custom made machine, shown in Figure 4, and hemispherical impactors of $0.203 \mathrm{~m}$ in diameter. The tup was dropped from a height of $1.295 \mathrm{~m}$ in order to obtain a drop velocity of $4.7 \mathrm{~m} / \mathrm{s}$. The plates were bolted down to steel plates, which were bolted to the impact test frame. In these tests, membrane action was significant since the panel's motion was restricted in the horizontal direction. The masses dropped were $340 \mathrm{~kg}$ (750lbs) (Test A), $455 \mathrm{~kg}$ (1003lbs) (Test B), and 682kg (1503lbs) (Tests C and D). Strain gauge readings were taking at various locations of these plates. Two other plates, 'large2(1)' and 'large2(2)' of size $1.37 \times 1.37 \times 0.038 \mathrm{~m}^{3}\left(4.5 \times 4.5 \mathrm{ftx} 1.5 \mathrm{in}^{3}\right)$, were similarly tested but using fully clamped boundary conditions instead. A summary of plate dimensions and test characteristics is presented in Table 3.

The damage incurred by the plates was measured by visual inspection of each face. Generally speaking, the discoloured areas can be directly related to delaminated regions. This method of measuring the delamination can only be approximate as the exact location of the delaminated plies cannot be obtained in this way. As only an educated guess can provide, we can speculate that the 'lighter discolouration' lies in the quarter of the plate nearer the surface inspected and the 'darker discolouration' lies nearer the plate centre. For the small plates, the single discoloured region lies in the half of the plate nearest the inspected face.

\subsection{Cyclic testing}

Cyclic tests were performed on woven E-glass/ Derakane 8084 vinyl-ester coupons. Three coupons were tested in the warp and weft directions in both tension and compression. The loading frequency was carried out at $0.5 \mathrm{~Hz}$ under strain control. The strain was applied in increments of 0.0025 and five loading cycles were carried out at every new increment of strain. The test data are useful in obtaining an approximation for the matrix damage initiation strain and the fibre damage initiation strain. A typical plot of strain versus damage in the warp direction is shown in Figure 5 for cycling under tension. The tests terminated earlier for the coupons tested under compression over those under tension.

The actual termination of the cyclic tests took place when audible pops were heard and the mean strain shifted causing a shift in the mean load in the direction of loading. It is difficult to know with certainty the exact point at which fibre cracking initiated however a reasonable approximation was taken as the termination of the cyclic tests, based on this information and then further examination of the tested coupons. The strain at this point is $\varepsilon_{\mathrm{f}}$. This 
strain value was recorded for the warp and weft directions for tension and compression and used in the damage function of Equation (15) as shown above.

In order to obtain the slope between $d_{I}(=0)$ and $d_{I I}$ in Figure 1 and Figure 2, the $d_{I I}$ must be obtained from these cyclic tests. The $\mathrm{d}_{\mathrm{II}(\mathrm{i})}$ parameter is simply derived by obtaining the tangent of the stress-strain curve for the last load cycle before the start of fibre damage (stage 2 damage), thus providing the degraded modulus at the end of damage phase 1, $\mathrm{E}_{\mathrm{II}(\mathrm{i})}$, for each of the two orthogonal in-plane directions, i.e. $\mathrm{E}_{\mathrm{III})}$ and $\mathrm{E}_{\mathrm{II}(2)}$. The stiffness $\mathrm{E}_{\mathrm{II}(\mathrm{i})}$ can therefore be directly related to $\mathrm{d}_{\mathrm{II}(\mathrm{i})}$ using Equation (23).

$d_{I I(i)}=\frac{E_{i}^{0}-E_{I I(i)}}{E_{i}^{0}}$

The data reveals that a larger amount of damage was suffered by the tensile coupons per unit strain. The tests also show that the warp direction is stronger than the weft direction and generally develops a little less damage at the same loading strains. The damage property parameters used in Equation (15) are shown in

\begin{tabular}{|l|l|l|l|}
\hline Cyclic testing & $\boldsymbol{\varepsilon}_{\mathbf{f}}$ & $\boldsymbol{\varepsilon}_{\max }$ & $\mathbf{d}_{\text {II }}$ \\
\hline Warp, tensile & 0.0225 & 0.04 (Williams et al.) & 0.17 \\
\hline Warp, compressive & -0.015 & -0.04 & 0.035 \\
\hline Weft, tensile & 0.0208 & 0.04 & 0.23 \\
\hline Weft, compressive & -0.015 & -0.04 & 0.027 \\
\hline
\end{tabular}

Table .

\section{Results and discussion \\ 4.1. Small plate impacts}

The results for the small plate impact tests for the three different tup sizes are shown in

\begin{tabular}{|c|c|c|c|c|c|c|c|}
\hline Test & $\begin{array}{c}\text { Tup velocity } \\
\mathrm{ms}^{-1}\end{array}$ & $\begin{array}{c}\text { Mass/ } \\
\mathrm{kg}\end{array}$ & $\begin{array}{l}\text { Contact } \\
\text { Force/ } \\
\text { kN }\end{array}$ & $\begin{array}{c}\text { Midpoint } \\
\text { displacement } \delta / \\
\mathrm{m} \\
{[\mathrm{FE} \text { in } \mathrm{m}]}\end{array}$ & $\begin{array}{c}\text { Test, damage size } \\
\text { (Top) } / \mathrm{m} \\
{[\mathrm{FE} \text { in } \mathrm{m}](\text { cohesive }} \\
\text { layer)* }\end{array}$ & $\begin{array}{c}\text { Test, damage size } \\
(\text { Bottom }) / \mathrm{m} \\
\\
{[\mathrm{FE} \text { in } \mathrm{m}] \text { (cohesive layer)* }}\end{array}$ & $\begin{array}{c}\text { Energy } \\
\text { Level } \\
\text { / J }\end{array}$ \\
\hline 1 & 4.59 & 8.55 & 15.15 & 0.0119 & $\begin{array}{l}0.0381 \times 0.0254 \\
{[0.0253 \times 0.016]}\end{array}$ & $\begin{array}{l}0.0381 \times 0.0381 \\
{[0.0253 \times 0.022]}\end{array}$ & 91.52 \\
\hline 2 & 4.572 & 13.33 & 20.35 & $\begin{array}{l}0.0141 \\
{[0.016]}\end{array}$ & $\begin{array}{c}0.03175 \times 0.0254 \\
{[0.0492 \times 0.035](\mathrm{c} 1)}\end{array}$ & $\begin{array}{c}0.0381 \times 0.0381 \\
{[0.0318 \times 0.0286](\mathrm{c} 8)}\end{array}$ & 140.57 \\
\hline 3 & 4.581 & 15.87 & & $\begin{array}{c}0.0158 \\
{[0.015]} \\
\text { (Partial Penetration) }\end{array}$ & $\begin{array}{c}0.0381 \times 0.0254 \\
{[0.0492 \times 0.0438](\mathrm{c} 6,8)} \\
0.03175 \times 0.0254 \\
{[0.0492 \times 0.035](\mathrm{c} 7,8)}\end{array}$ & $\begin{array}{c}0.0381 \times 0.0508 \\
{[0.0552 \times 0.0492](\mathrm{c} 1,2)} \\
0.0381 \times 0.0381 \\
{[0.0192 \times 0.0192](\mathrm{c} 1-3)}\end{array}$ & 165.82 \\
\hline $4^{+}$ & 4.584 & 18.37 & 17.73 & Penetration & $\begin{array}{c}0.03175 \times 0.0254 \\
{[0.0436 \times 0.022](\mathrm{c} 8)}\end{array}$ & $\begin{array}{c}0.0381 \times 0.0381 \\
{[0.022 \times 0.0436](\mathrm{c} 1,2)}\end{array}$ & 193 \\
\hline 5 & 4.615 & 18.37 & 22.52 & Penetration & $\begin{array}{c}0.0381 \times 0.0254 \\
{[0.0492 \times 0.035](\mathrm{c} 8)}\end{array}$ & $\begin{array}{c}0.0381 \times 0.0381 \\
{[0.0318 \times 0.0318)(\mathrm{c} 1,2)} \\
\end{array}$ & 195.6 \\
\hline 6 & 4.594 & 18.62 & 26.98 & Penetration & & & 196 \\
\hline \multicolumn{8}{|c|}{ Table, } \\
\hline Test & $\begin{array}{c}\text { Tup velocity } \\
\mathrm{ms}^{-1}\end{array}$ & $\begin{array}{c}\text { Mass/ } \\
\mathrm{kg}\end{array}$ & $\begin{array}{l}\text { Contact } \\
\text { Force/ } \\
\mathrm{kN}\end{array}$ & $\begin{array}{c}\text { Midpoint } \\
\text { displacement } \delta / \\
\mathrm{m}\end{array}$ & $\begin{array}{c}\text { Test, damage size } \\
\text { (Top) / } \mathrm{m} \\
{[\text { FE in } \mathrm{m}] \text { (cohesive }}\end{array}$ & $\begin{array}{c}\text { Test, damage size } \\
\text { (Bottom) } / \mathrm{m} \\
{[\text { FE in } \mathrm{m} \text { (cohesive layer)* }}\end{array}$ & $\begin{array}{c}\text { Energy } \\
\text { Level } \\
/ \mathrm{J}\end{array}$ \\
\hline
\end{tabular}




\begin{tabular}{|c|c|c|c|c|c|c|c|}
\hline & & & & [FE in $\mathrm{m}]$ & layer)* & & \\
\hline 9 & 4.593 & 18.70 & 24.93 & $\begin{array}{l}0.0159 \\
{[0.017]}\end{array}$ & $\begin{array}{c}0.03175 \times 0.0254 \\
{[0.044 \times 0.044](\mathrm{c} 5)}\end{array}$ & $\begin{array}{c}0.0381 \times 0.03175 \\
{[0.038 \times 0.038](\mathrm{c} 3)}\end{array}$ & 195.51 \\
\hline 10 & 4.596 & 20.34 & 27.86 & $\begin{array}{l}0.0165 \\
{[0.018]}\end{array}$ & $\begin{array}{c}0.0381 \times 0.03175 \\
{[0.052 \times 0.038](\mathrm{c} 7)}\end{array}$ & $\begin{array}{c}0.0381 \times 0.03175 \\
{[0.043 \times 0.033](\mathrm{c} 4)}\end{array}$ & 217.41 \\
\hline 7_R & 4.596 & 23.69 & 27.74 & $\begin{array}{c}0.0186 \\
\text { (Partial Penetration) } \\
{[0.019]}\end{array}$ & $\begin{array}{r}0.03175 \times 0.0381 \\
{[0.0478 \times 0.043](\mathrm{c} 7)}\end{array}$ & $\begin{array}{c}0.04445 \times 0.04445 \\
{[0.0382 \times 0.033](\mathrm{c} 2 \& 4)}\end{array}$ & 247.59 \\
\hline
\end{tabular}

Table and

\begin{tabular}{|c|c|c|c|c|c|c|c|}
\hline Test & $\begin{array}{c}\text { Tup velocity } \\
/ \\
\text { ms-1 }\end{array}$ & $\begin{array}{c}\text { Mass/ } \\
\mathrm{kg}\end{array}$ & $\begin{array}{c}\text { Contact } \\
\text { Force/ } \\
\text { kN }\end{array}$ & \begin{tabular}{|c|} 
Midpoint \\
displacement $\delta$ \\
$/$ \\
$\mathrm{m}$ \\
{$[\mathrm{FE} \mathrm{in} \mathrm{mm}]$} \\
\end{tabular} & $\begin{array}{c}\text { Test, damage size } \\
\text { (Top) } / \mathrm{m} \\
{[\text { FE in m](cohesive }} \\
\text { layer)* }\end{array}$ & $\begin{array}{l}\text { Test, damage size } \\
\text { (Bottom) } / \mathrm{m} \\
{[\mathrm{FE} \text { in } \mathrm{m}] \text { (cohesive }} \\
\text { layer)* }\end{array}$ & $\begin{array}{c}\text { Energy } \\
\text { Level } \\
\text { / J }\end{array}$ \\
\hline $\begin{array}{c}11 \\
(281) \\
\end{array}$ & 4.60553 & 20.26 & 22.28 & $\begin{array}{l}0.0206 \\
{[0.019]}\end{array}$ & $\begin{array}{c}0.04445 \times 0.0381 \\
{[0.073 \times 0.036](\mathrm{c} 8)}\end{array}$ & $\begin{array}{c}0.0381 \times 0.0381 \\
{[0.0437 \times 0.0382](\mathrm{c} 1)}\end{array}$ & 211.71 \\
\hline $\begin{array}{c}12 \\
(282) \\
\end{array}$ & 4.60553 & 24.32 & 23.43 & $\begin{array}{l}0.0223 \\
{[0.025]}\end{array}$ & $0.04445 \times 0.0381$ & $0.0381 \times 0.0381$ & 263.41 \\
\hline $\begin{array}{c}13 \\
(283) \\
\end{array}$ & 4.60858 & 26.19 & 24.86 & $\begin{array}{r}0.0229 \\
{[0.02]}\end{array}$ & $\begin{array}{c}0.05715 \times 0.03175 \\
{[0.055 \times 0.029](\mathrm{c} 7,8)}\end{array}$ & $\begin{array}{c}0.0381 \times 0.0381 \\
{[0.0318 \times 0.035](\mathrm{c} 1-2)}\end{array}$ & 284.05 \\
\hline $\begin{array}{c}14 \\
(284)\end{array}$ & 4.69087 & 26.19 & 24.57 & $\begin{array}{l}0.0236 \\
{[0.028]}\end{array}$ & $\begin{array}{c}0.0381 \times 0.0381 \\
{[0.068 \times 0.036](\mathrm{c} 6-8)}\end{array}$ & $\begin{array}{c}0.04445 \times 0.0381 \\
{[0.055 \times 0.0494](\mathrm{c} 1,2)}\end{array}$ & 294.16 \\
\hline $\begin{array}{c}15 \\
(285) \\
\end{array}$ & 6.2088 & 26.19 & 28.13 & $\begin{array}{l}0.0376 \\
{[0.024]}\end{array}$ & $\begin{array}{c}0.03175 \times 0.03175 \\
{[0.0976 \times 0.1778](\mathrm{c} 8)}\end{array}$ & $\begin{array}{c}0.05715 \times 0.04445 \\
{\left[0.072 \times 0.1778^{* *}\right](\mathrm{c} 1)}\end{array}$ & 495.85 \\
\hline $\begin{array}{c}16 \\
(286)\end{array}$ & 7.13 & 26.19 & 29.40 & $\begin{array}{l}0.0546 \\
{[0.03]}\end{array}$ & $\begin{array}{c}0.06985 \times 0.0508 \\
{[0.055 \times 0.0318](\mathrm{c} 6-8)}\end{array}$ & $\begin{array}{c}0.03175 \times 0.03175 \\
{[0.0794 \times 0.0492](\mathrm{c} 1)}\end{array}$ & 664.9325 \\
\hline
\end{tabular}

Table. The tests are shown in order of impact energy. The finite element delamination predictions are given underneath the experimental results, for the top and bottom half of the plates using a full ( 8 layer) cohesive layer model.

The effect of using a damage model over a no-damage FE model is less significant on the contact force results for the smaller incident kinetic energy (IKE) impact tests, as demonstrated with analysis test 9M(195J) in Figure 6 but more so with the larger impact energy tests such as test $16 \mathrm{~L}(665 \mathrm{~J})$ in Figure $7(\mathrm{a})$. The analysis name gives information on the test number; the size of the tup used, ' $\mathrm{S}$ ' for small $(12.7 \mathrm{~mm})$, 'M' for medium $(25.4 \mathrm{~mm})$ and ' $\mathrm{L}$ ' for large $(38 \mathrm{~mm})$; and the impact energy. Modelling delamination with cohesive layers not only reduces the peak contact force but also appears to stabilize the shape of the contact force, also demonstrated with Figure 6 for a 4 cohesive layer model. A likely reason for this is the extra energy absorption at these layers. Without the cohesive layers, plotted as 'solid 5', the excess energy that would normally go into delamination goes into more matrix and fibre damage, causing the elements to excessively deform. Inclusion of these cohesive layers not only has the effect of further reducing the stiffness of the plate but further decreases the detection of some of the higher frequency components.

Significant fibre failure associated with high impact energies is demonstrated with a sudden drop in contact force, which was predominant with test $23 \mathrm{M}(270 \mathrm{~J})$ in Figure 7(b). The FE model of this test becomes very unstable at this point of impact, and although it provides a good peak contact force, the unloading part of the curve contains many sporadic peaks that are no reflection of the actual contact behaviour of the panel. Degrading the through-thickness properties of the woven ply material positively reduces the contact force but also adds to some de-stabilization of the analyses occurs with decrease in tup size and increase in incident energy.

There is trend amongst all the analyses that shows an increase in the asymmetry of the contact force-time plots with increase in impact energy, which indicates an increase in damage [21]. The number of cohesive elements used and the transverse degradation of the woven plies using the TIP damage model have a particularly prominent effect on the analyses. Modelling the full number of cohesive layers and applying the TIP damage model can decrease the transverse stiffness to such an extent that it has an obvious knock-on effect on the in-plane matrix and fibre damage and delamination predictions. This does not happen when only half the number of cohesive regions is modeled. Although more fibre damage is predicted with the 8 layer model, the maximum area of matrix damage and delamination is better captured than with the 4 layer model. This effect is enhanced with increase in incident energy. 
Although the difference in damage prediction appears significant enough to affect the contact force output, these are in fact only marginally affected because the most severe development of the transverse damage occurs towards the end of the impact phase when the plate is near its maximum deflection.

The large element distortion is most severe with the small impact tests, seen primarily at the bottom of the plate centre. Many of the small tup impact tests caused partial or full penetration of the plate and this type of event is not accounted for in the model. Ideally, to reduce the element distortion in these impact cases, the failed elements would need to be deleted/'eroded'. However, this is not practical or realistic for the mesh densities considered, and would in reality only add to the model's instability. Then again, a very fine mesh for models of this size and larger would take weeks to run. Figure 8(a) and (b) shows the transverse shear modulus $E_{31}$ contours for the lowest and highest IKE small tup impact tests $1 \mathrm{~S}(91.5 \mathrm{~J})$ and test $6 \mathrm{~S}(196 \mathrm{~J})$. Significantly higher fibre damage is predicted for test $6 \mathrm{~S}(196 \mathrm{~J})$ (indicated with areas of lowest modulus), which in reality incurred tup penetration.

The large tup simulations developed the least element distortion. Test $15 \mathrm{~L}(495 \mathrm{~J})$ and test $16 \mathrm{~L}(664 \mathrm{~J})$ benefited the most out of all the simulations from the full 8 cohesive layer model and the TIP damage model. When only 4 cohesive layers were modeled for these test simulations, the layers severely over-delaminated causing the analyses to stop prematurely. For these particular tests the energy was largely used in creating delamination, more so than matrix or fibre damage and a model with only half the number of cohesive layers absorbed more energy per layer than one with 8 . This makes sense as the effect of a large tup diameter more closely resembles the effect of an air blast or underwater shock load and these principally create transverse damage in the form of delamination [47]. The interface between two plies is a weakness in the laminate and therefore delamination is an easier damage mode. The transverse damage predictions at the woven plies using the TIP model was also more spread out than with the smaller tup impact simulations. Test measurements indicating the extent of through-thickness damage (i.e. in-plane cracks within the plies) are not available therefore the FE transverse damage area predictions cannot be validated.

Based on the above, the trend appears to be generally reflective of rather harsh transverse damage criteria at the woven plies for a full cohesive layer model. Despite this, the out-of-plane displacements are relatively well predicted in all the analyses, with a general trend towards a slight over-prediction of the contact force and underprediction of the displacement with the large tup-large energy impact tests. The improvements in using the proposed damage model are very significant. Figure 9, Figure 10 and Figure 11 show the contact force plotted against the impact energy for analyses modelling full damage 'dam' and no damage 'no dam', and the test results. The relationship between increase in incident kinetic energy and increase in contact force is demonstrated, however the relationship between the incident kinetic energy and the largest delamination measured is not as clear, as shown with Figure 12. This is in contrast to what was reported by Zhou and Greaves [1], although unlike the present work where the impact or mass is varied but the impact velocity is kept constant. their tests varied the incident velocity only.

A plot of displacement against contact force for several of the 1 inch tup tests (low to intermediate impact energies), Figure 13, shows some important features during the loading event. The plate width-to-thickness ratio of these plates is large enough for membrane action to take effect and this is apparent with the increase in the stiffness of the plate from the start to the finish of loading. Some of the peaks and troughs present in all the experimental plots are replicated in the FE models, here demonstrated for various medium tup impact tests and one simulation. One obvious difference between the test and FE results includes the lack of un-recoverable (irreversible) energy in the numerical analysis and its rotational shift relative to the test by over-predicted out-of-plane displacements and longer contact times. At peak '1', the FE model predicts no damage, and the reduction in contact force may be attributed to the compression of the top element and the contact definition. Peak ' 2 ', coincides with the start of in-plane damage at the bottom of the plate and shear induced delamination. At peak ' 3 ' significant drops in the in-plane modulus takes place for those elements at the centre of the plate, particularly at the bottom of the plate, and some fibre damage is created. From this point onwards more elements in and around the impact site begin to loose stiffness, and further significant delamination takes place. At peak '4', full failure occurs and unloading begins. Throughout the loading history, the plate elements towards the top of the plate degrade less in comparison to the bottom of the plate.

The results are also detailed in

\begin{tabular}{|c|c|c|c|c|c|c|c|}
\hline Test & $\begin{array}{c}\text { Tup velocity / Mass/ } \\
\mathrm{ms}^{-1}\end{array}$ & $\begin{array}{c}\text { Contact } \\
\mathrm{kg}\end{array}$ & $\begin{array}{c}\text { Force/ } \\
\mathrm{kN}\end{array}$ & $\begin{array}{c}\text { Midpoint } \\
\text { displacement } \delta / \\
\mathrm{m} \\
{[\text { FE in } \mathrm{m}]}\end{array}$ & $\begin{array}{c}\text { Test, damage size } \\
\text { (Top)/m } \\
{[\mathrm{FE} \text { in } \mathrm{m}](\text { cohesive }} \\
\text { layer)* }\end{array}$ & $\begin{array}{c}\text { Test, damage size } \\
\text { (Bottom)/m }\end{array}$ & $\begin{array}{c}\text { Energy } \\
\text { Level } \\
/ \mathrm{FE} \text { in m] }(\text { cohesive layer)* }\end{array}$ \\
\hline 9 & 4.593 & 18.70 & 24.93 & 0.0159 & $0.03175 \times 0.0254$ & $0.0381 \times 0.03175$ & 195.51 \\
\hline
\end{tabular}




\begin{tabular}{|c|c|c|c|c|c|c|c|}
\hline & & & & {$[0.017]$} & {$[0.044 \times 0.044](\mathrm{c} 5)$} & {$[0.038 \times 0.038](\mathrm{c} 3)$} & \\
\hline 10 & 4.596 & 20.34 & 27.86 & $\begin{array}{l}0.0165 \\
{[0.018]}\end{array}$ & $\begin{array}{c}0.0381 \times 0.03175 \\
{[0.052 \times 0.038](\mathrm{c} 7)} \\
\end{array}$ & $\begin{array}{c}0.0381 \times 0.03175 \\
{[0.043 \times 0.033](\mathrm{c} 4)}\end{array}$ & 217.41 \\
\hline 7_R & 4.596 & 23.69 & 27.74 & $\begin{array}{c}0.0186 \\
\text { (Partial Penetration) } \\
{[0.019]}\end{array}$ & $\begin{array}{r}0.03175 \times 0.0381 \\
{[0.0478 \times 0.043](\mathrm{c} 7)}\end{array}$ & $\begin{array}{c}0.04445 \times 0.04445 \\
{[0.0382 \times 0.033](\mathrm{c} 2 \& 4)}\end{array}$ & 247.59 \\
\hline
\end{tabular}

Table 6. Medium tup 'M' (25.4mm dia.) - small plate test results and FE delamination predictions, using a co8_p2t2 mesh. 'c1' is the cohesive layer nearest the bottom of the plate and ' $\mathbf{c 8}$ ' is nearest the top. The maximum area of damage appears quite extensive, however the predicted modulus reduction in these wider regions is only small, comprising largely of matrix cracking only. The model shows that more in-plane damage is seen at the bottom than at the top of the plate, correlating well with the trends recorded by Mouritz [48]. Cracking of both the matrix and glass fibres was observed in the tests, which is evident in the FE simulations.

The delamination damage for test $13 \mathrm{M}(284 \mathrm{~J})$ is shown in Figures 15(a) and (b). Although the widest area of damage was seen from the top of the plate in (b), Figures 15 (a) shows larger inter-ply separation at the bottom of the plate caused by the release of the residual transverse tensile transverse stresses on cutting the plate in half. It is clear from these figures that the largest delaminations occur inside, correctly modeled but over-predicted with the FE analyses. With all the analyses, failure of the cohesive elements during the compression phase occurs due to the shear stresses only because the normal transverse stress contribution during the compression phase is excluded from the failure criteria. Therefore the effect of delamination on the peak contact force is governed by the transverse shear stresses only. It is during the tensile phase (when the tup moves away), that some of these central cohesive elements begin to fail under normal transverse tension. Besides the extensive through-thickness delamination seen in most tests and their simulations, the maximum bending stresses are foremost responsible for large amounts of matrix and fibre damage formation at the top and bottom of the plate, accentuated in the analyses at the bottom of the plate due to the effects of localized compression at the top of the plate and the tensile-tendency of the normal transverse stresses at the bottom plies.

A few of the medium tup impact analyses were evaluated for variations in the damage parameter $\mathrm{d}_{\text {II }}$ of up to $50 \%$, keeping all other parameters constant, including the strain at the start of fibre damage, $\varepsilon_{\mathrm{f}}$, it was found that it had a negligible, effect on the contact force . It may be that the rate of damage up to strain $\varepsilon_{\mathrm{f}}$ is not that significant, although this would have to be properly verified by testing even larger values of dII and for other impact conditions. Moreover, increasing the rate in the early part of the loading curve but keeping all other parameters constant, brings about a decrease in the rate of damage after a strain value of $\varepsilon_{\mathrm{f}}$. Differentiating between compressive and tensile inplane strains made a negligible difference to the maximum out-of-plane displacement but had the effect of increasing the maximum contact force by a mere $3 \%$.

\subsection{Large plate impacts}

The finite element results show that the contact force is slightly under-predicted for the smaller mass impacts but good results are obtained with the largest mass $682 \mathrm{~kg}$ tup used in tests $\mathrm{C}$ and $\mathrm{D}$. The results for the no-damage model still show an under-prediction in the contact force for the lowest energy impact, test large1(A), but for test large 1(B) the peak contact force is close to the experimental value. A similar trend was seen with the large 2 plate analyses. It is therefore likely that the element type is a large contributor to the problem as it was found that the shells produced higher contact force predictions than the solid (continuum) elements for an analysis exclusive of damage. The maximum out-of-plane displacement and contact force results are shown in Figures 16 to Figures 17. The contact force predictions for the largest and thickest plates impacted, large2, were quite reasonable, as shown in Figure 18. Two examples of strain readings taken along the length and width of the plate, $100 \mathrm{~mm}$ and $190 \mathrm{~mm}$ from the plate centre respectfully are shown in Figure 19(a) and (b). The gauge reading labeled ' $\mathrm{g} 3$ ' is on the top face of the plate, mirroring gauge 17 shown labeled in Figure 21.

The Overall damage predictions correlated well with the experimental trend. The largest delaminations did appear inside the plate, not at the surfaces, although the analyses did over-predict the size of these regions. Figure 20 and Figure 21 are photos of the damage regions for large1(D) and the FE damage predictions in Figure 22. The damage experienced by plates large2(1) was less than that experienced by plate large1(B), both being impacted with almost 
the same tup mass and velocity. Although the large2(1) plate was clamped, this plate was almost twice the thickness and is reflected in the type of damage incurred. The largest delaminated layer was measured near the mid-plate which was predicted relatively well with the cohesive zone model. This indicates that this thick plate absorbed much of the energy transversely, and the transverse shear stresses being maximum at the mid-plane were probably largely responsible for the greater amount of delamination seen inside the plate and not near the surface. This is in contrast to large1(B) test which suffered fibre fracture at the top and particularly bottom face. The contact force and incident kinetic energy relationship for the large plate impacts is shown in Figure 23, showing a good correlation between the FE predictions and the test.

\section{Conclusion}

A simple $2 \mathrm{~d}$ damage model at the woven plies based on damage mechanics principles and separate transverse damage criteria has been presented for thick composite plates and validated for impact loading under simply supported boundary conditions. A global strain-based damage function initiates damage after which degradation of the in-plane and out-of-plane properties of the woven plies are treated separately using strain and stress functions respectfully. Delamination of the inter-ply regions is modeled with a cohesive zone model. The limited literature on impact modelling of marine composites is largely restricted to thin plates and do not include all failure modes. This paper shows how a full $3 \mathrm{~d}$ damage model is necessary to effectively model the behaviour of thicker plates under transverse loading.

It is observed that modelling $3 \mathrm{~d}$ damage at the ply level and delamination reduces the contact force by up to $42 \%$ compared to the no-damage model but generally increases the contact time and out-of-plane displacement compared to the experiment. Thick plates with relatively few plies (in this case 9) simulated with a $2 \mathrm{~d}$ damage model at the woven plies and cohesive layers at every inter-ply still give an over-predicted contact force. To reduce this it is necessary to model the transverse intra-laminar damage at the woven layers, although the model's degradation rules were a little too severe. Inserting cohesive zones in between every ply may not be computationally reasonable for plates with many layers and modelling fewer cohesive layers can still provide good results as long as throughthickness damage is incorporated at the plies.

It was found that in-plane and transverse intra-laminar damage modelling at the woven plies is the largest cause of reduction in contact force followed by the delamination model which also has the effect of stabilizing the contact behaviour through the absorption of some of the impact energy. The implementation of the damage model always improves the contact force, displacement and damage predictions over a no-damage model.

Although strain rate sensitivity is an issue which still needs addressing, one of the largest obstacles which must be over-come is the mesh sensitivity of the analyses, which prevents increasing the mesh size for the large plate analyses and results in long computational times. This is largely because of mesh constraints relating particularly to the mesh sensitivity of the cohesive zone model.

\section{Acknowledgements}

The authors are grateful for the financial support provided by the Office of Naval Research, Office of Naval Research Global and the Health and Safety Executive of the United Kingdom. This work is declared a work of the U.S. Government and is not subject to copyright protection in the United States. The last author (ASF) would like to thank his fellow colleague Dr. J. Ankersen of the Department of Aeronautics at Imperial College London for his assistance in clarifying some issues regarding the CDM model of this work. 


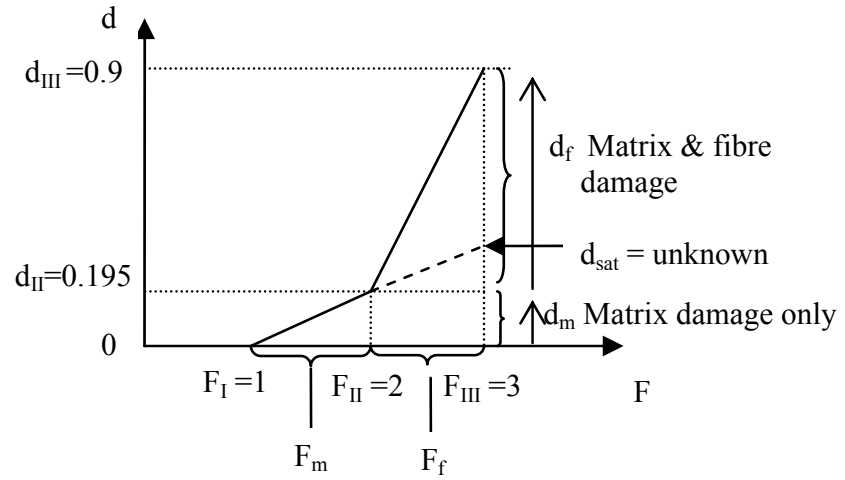

Figure 1. Damage parameter $d$ as a function of $F$, for a given orthogonal in-plane direction

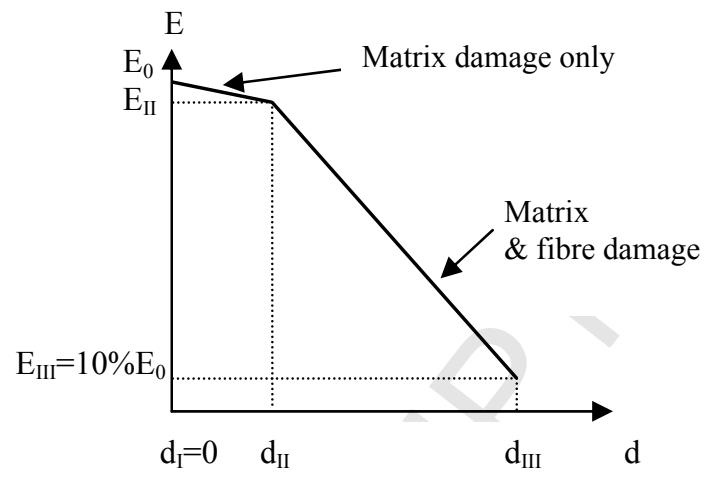

Figure 2. Modulus reduction as a function of $\mathrm{d}$, for a given orthogonal in-plane direction.

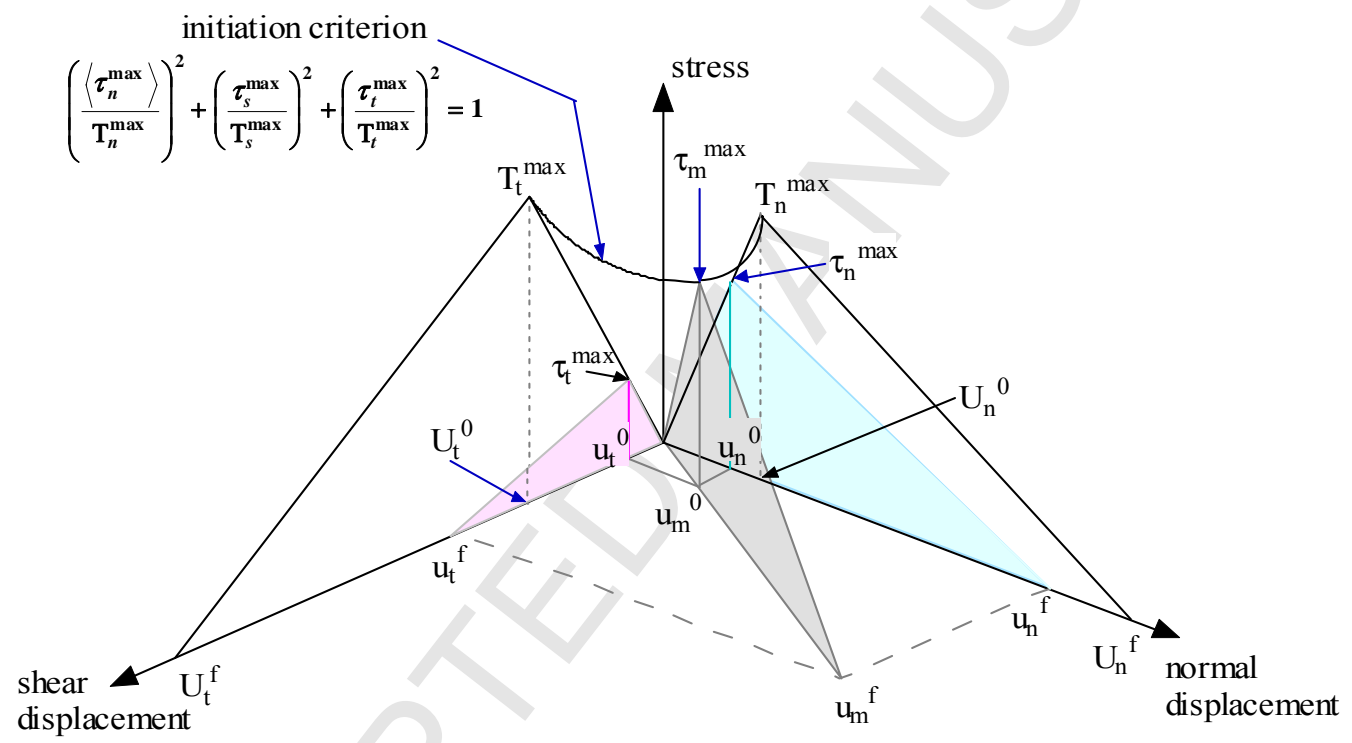

Figure 3. Mixed-mode traction-separation

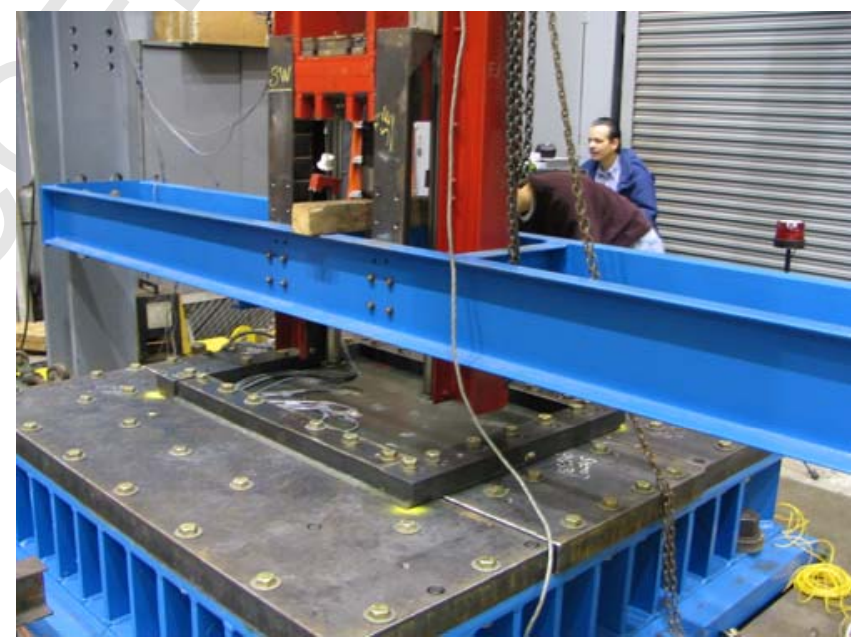

Figure 4. Impact rig for the large-scale plate tests 


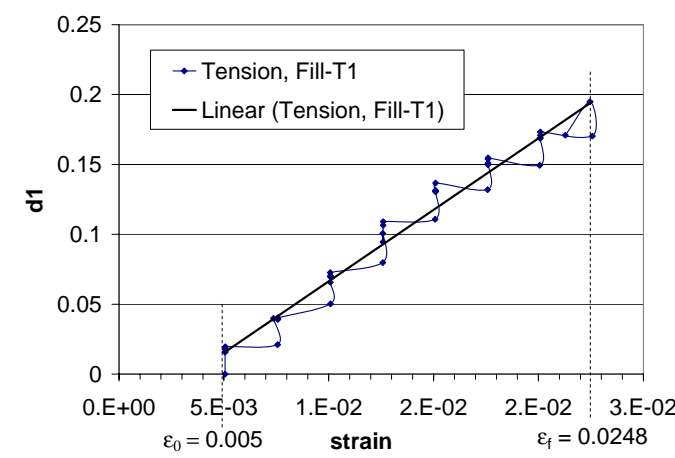

Figure 5. Strain versus damage, tensile cycling in the warp direction, coupon Warp-T2.

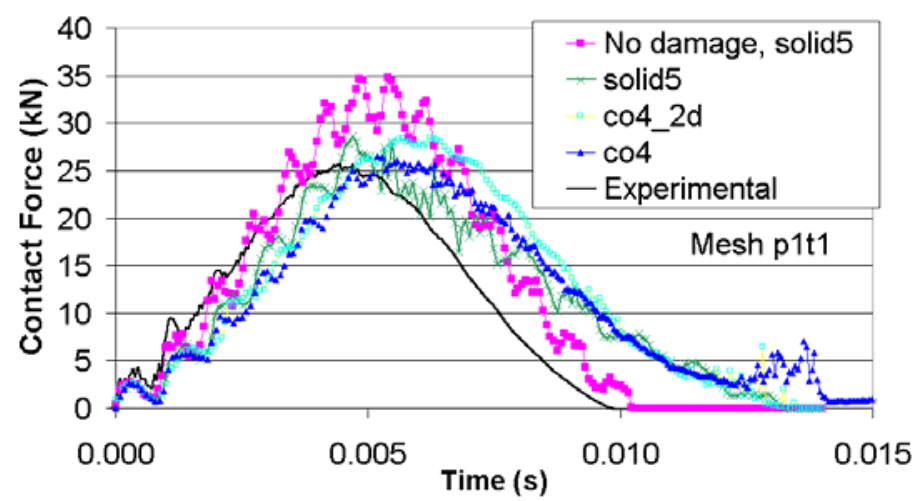

Figure 6. Contact force-time history for test $9 \mathrm{M}(195 \mathrm{~J})$ - test and various $\mathrm{FE}$ analyses.

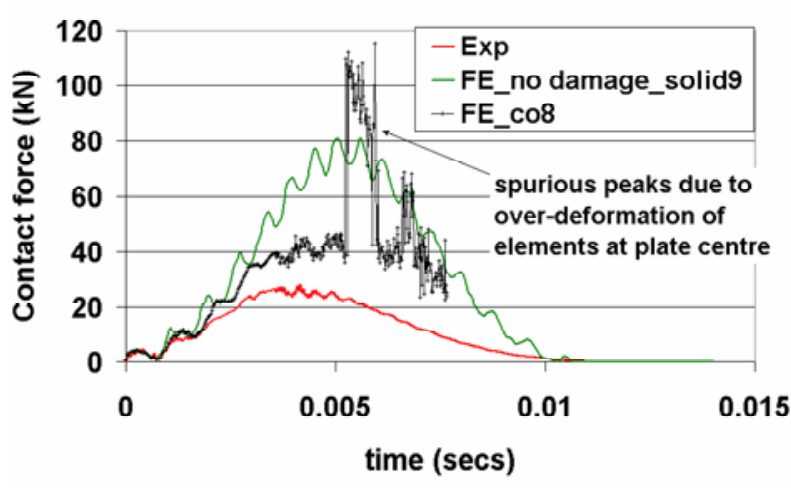

(a)

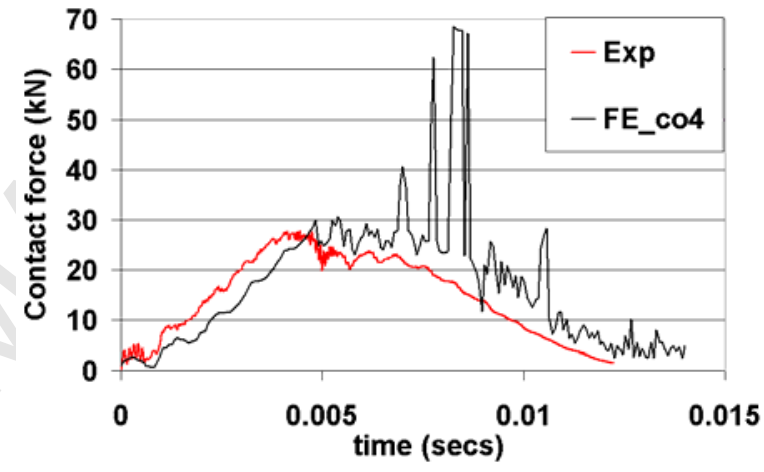

(b)

Figure 7. Contact force predictions for (a) test $16 \mathrm{~L}(665 \mathrm{~J})$, (b) test $23 \mathrm{M}(270 \mathrm{~J})$.

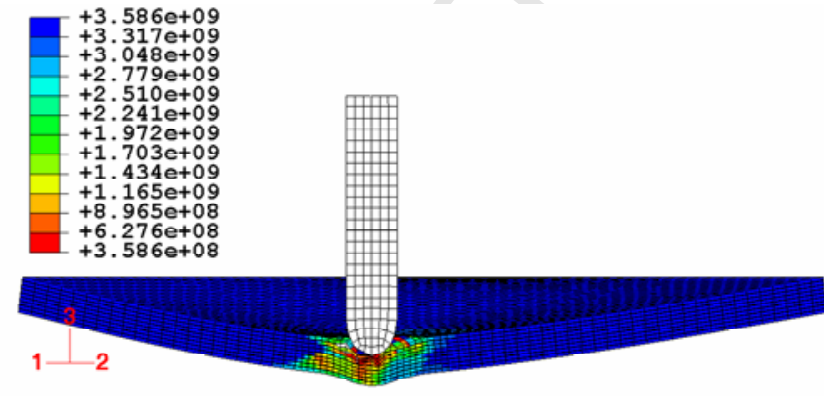

(a)

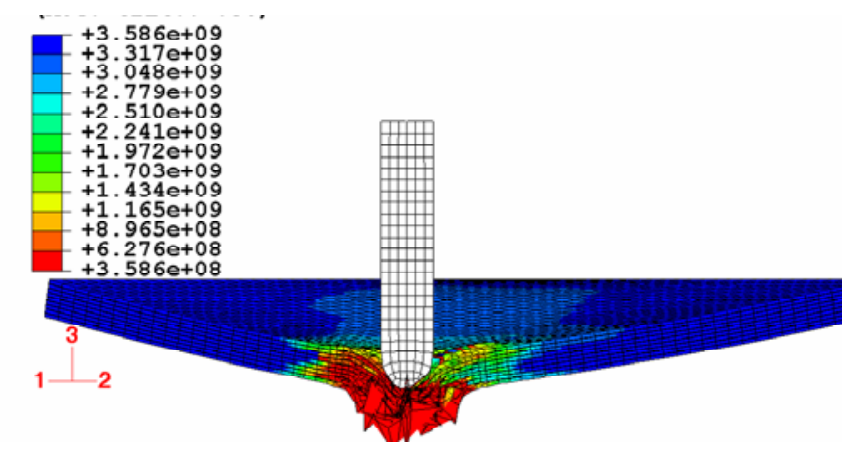

(b)

Figure 8. Transverse shear damage in 13 direction shown with transverse modulus contours $\mathrm{E}_{13}$, predicted for (a) test $1 \mathrm{~S}(95 \mathrm{~J})$ and (b) test6S, in Pa. 


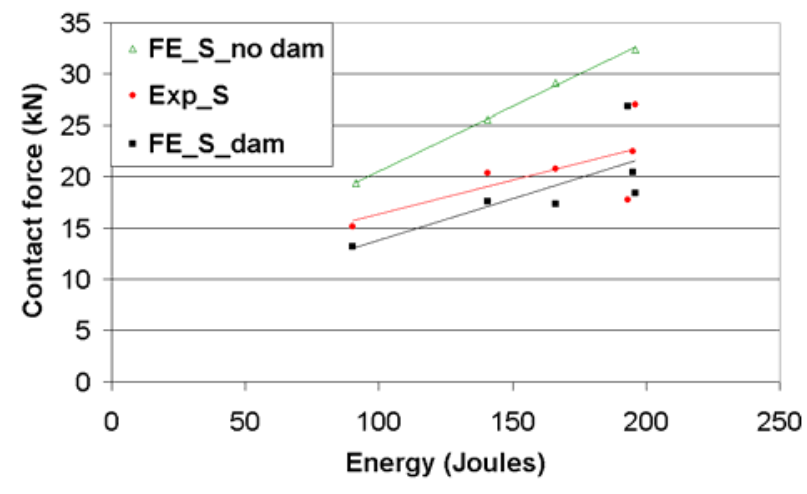

Figure 9. Contact force-impact energy plots for the small plate small tup impacts - test versus FE

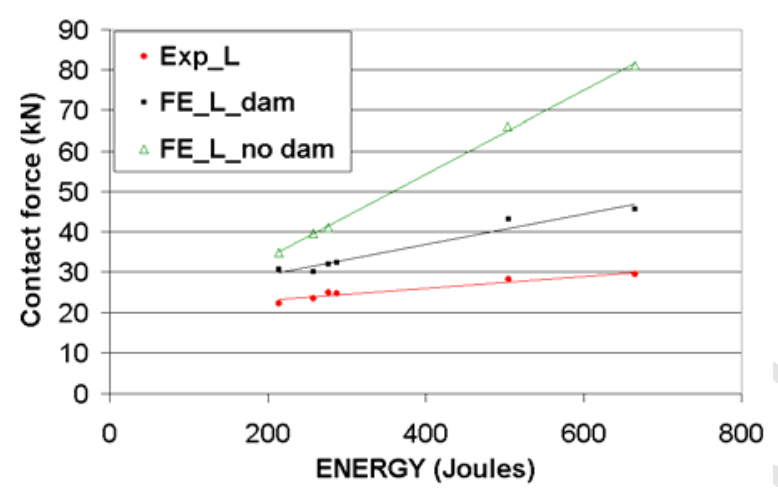

Figure 11. Contact force-impact energy plots for the small plate large tup impacts - test versus FE

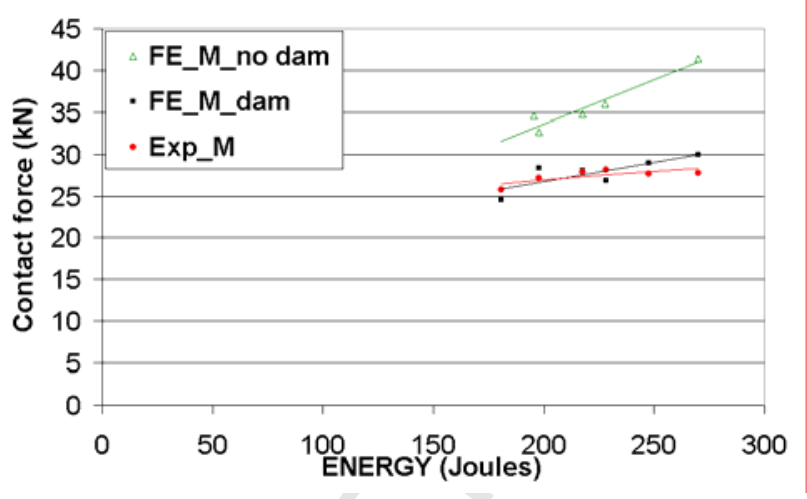

Figure 10. Contact force-impact energy plots for the small plate medium tup impacts - test versus FE

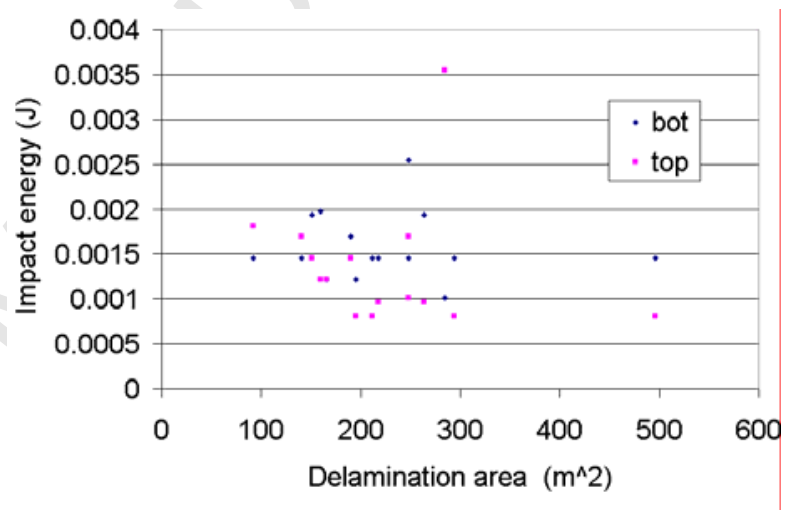

Figure 12. Maximum delamination area in the bottom and top half of the plate versus impact energy plots for the small plate large tup impacts - test versus FE

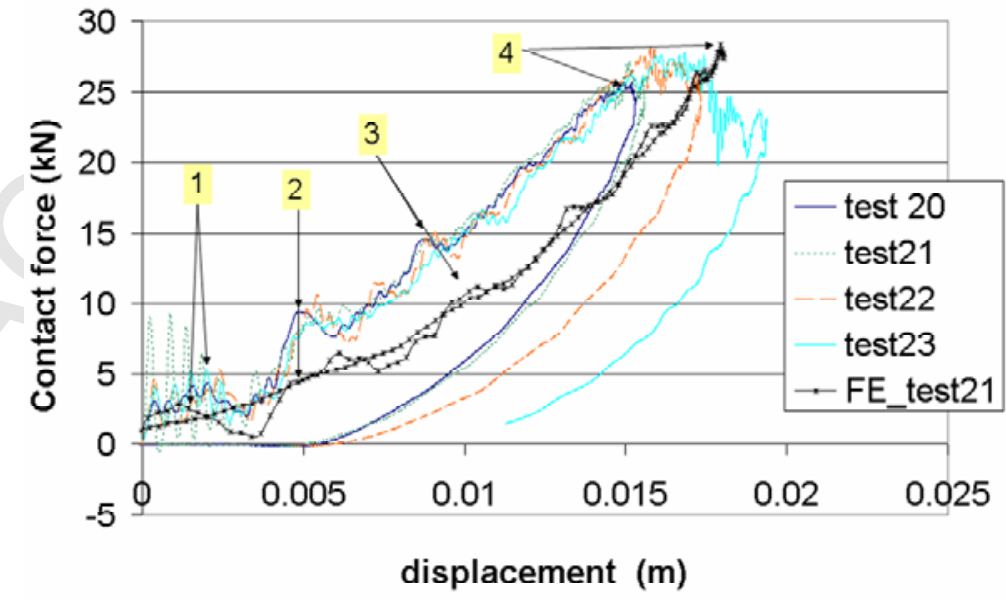

Figure 13. Displacement-contact force for a few of the medium tup impact tests 


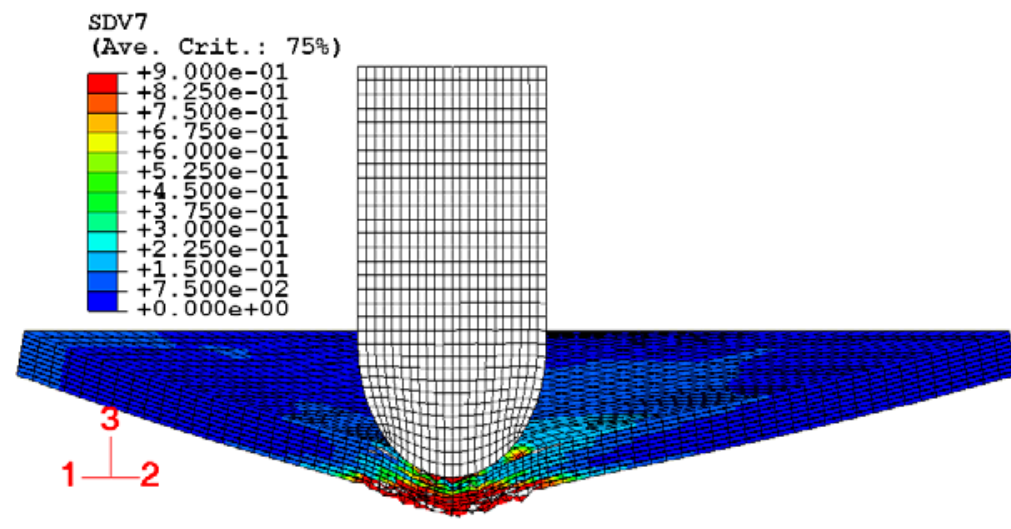

(a)

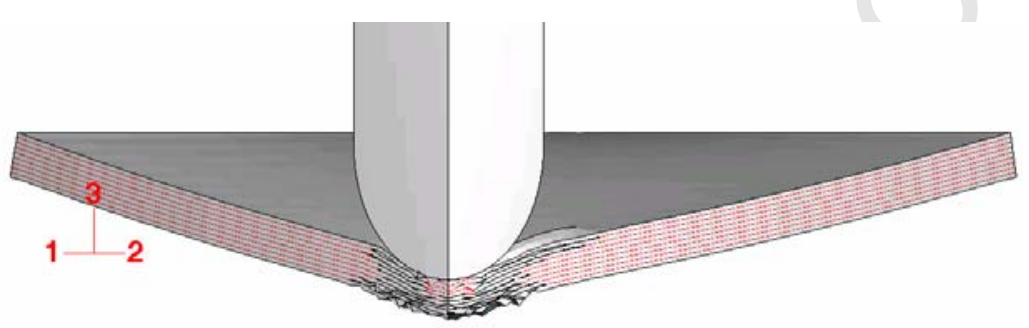

(b)

Figure 14. Damage predictions for test 13L(284J) with a 8 cohesive layer model, (a) matrix and fibre damage with variable $\mathrm{d}_{1}$, (b) delamination

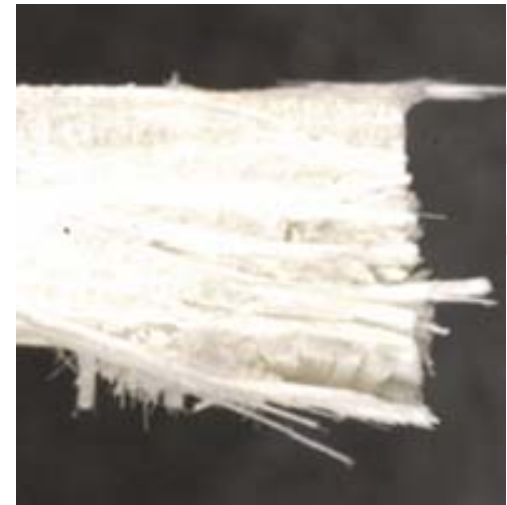

(a)

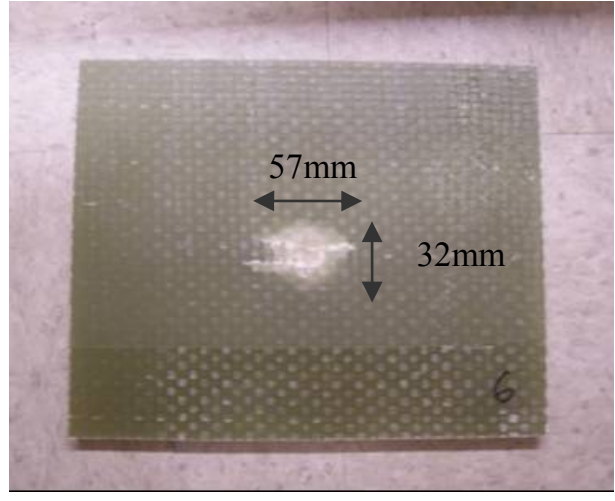

(b)

Figures 15. Delamination results for test 13M(284J), (a) cross-section of plate cut in half, (b) damage viewed from the top face 


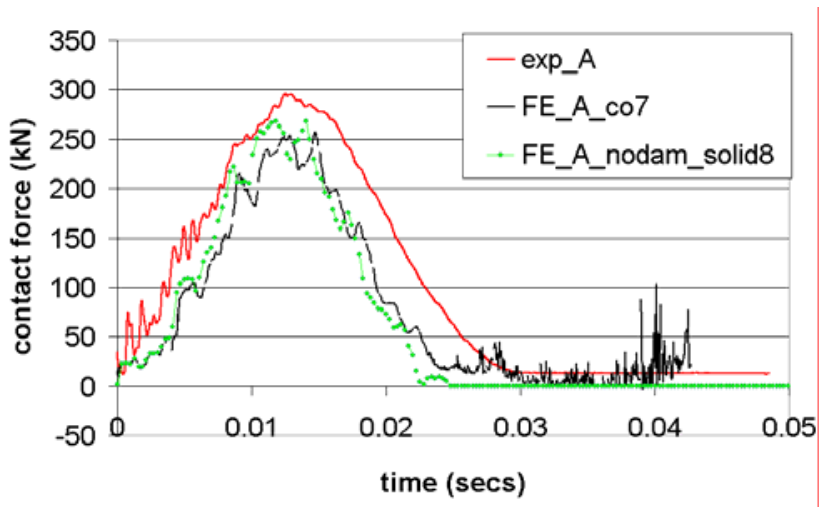

(a)

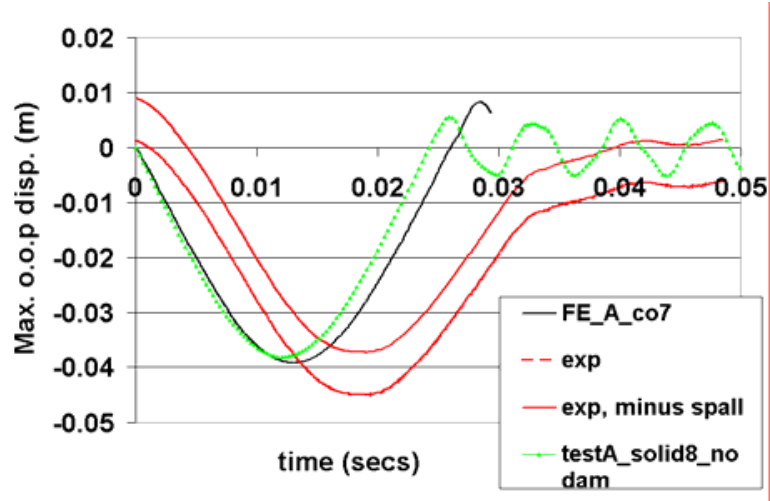

(b)

Figures 16. Large1(A), (a) out-of-plane displacement-time, (b) contact force-time histories

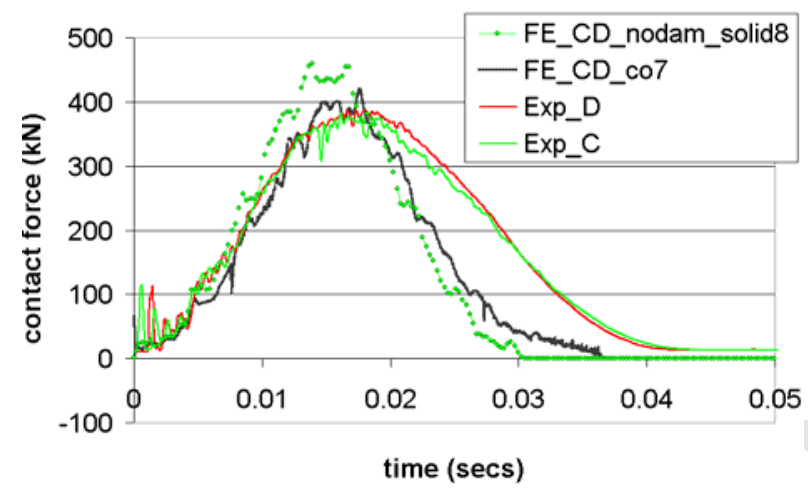

(a)

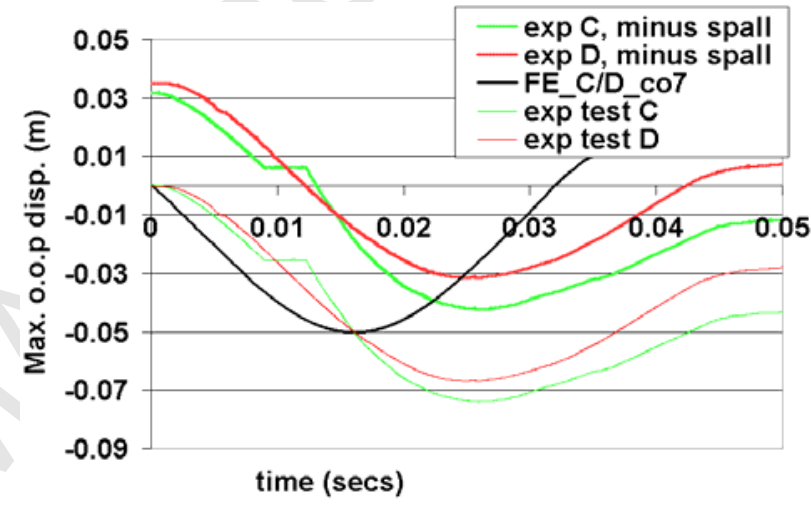

(b)

Figures 17.Large1(C) and (D), (a) max. out-of-plane displacement-time, (b) contact force-time histories

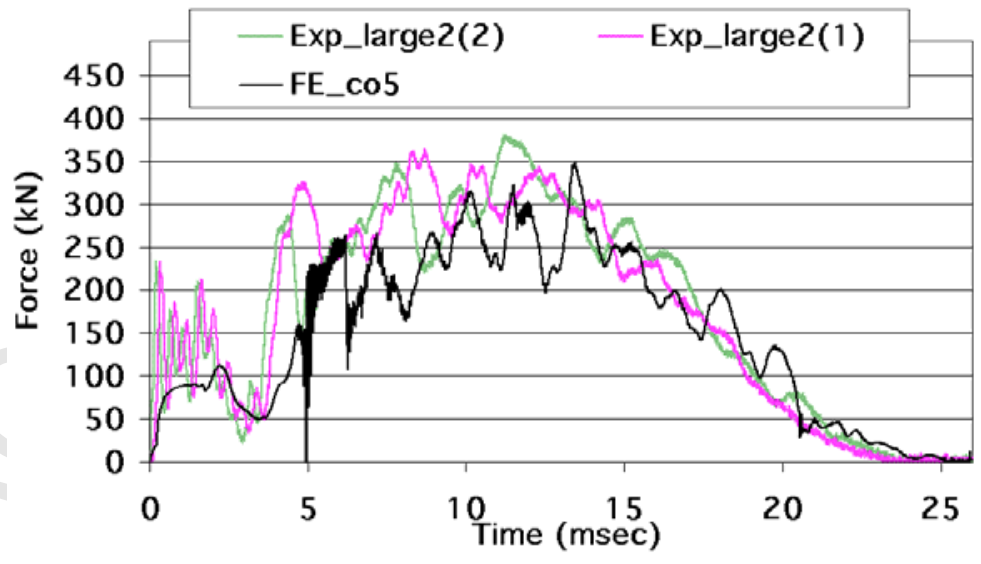

Figure 18. Contact force-time history for large2 plate tests 


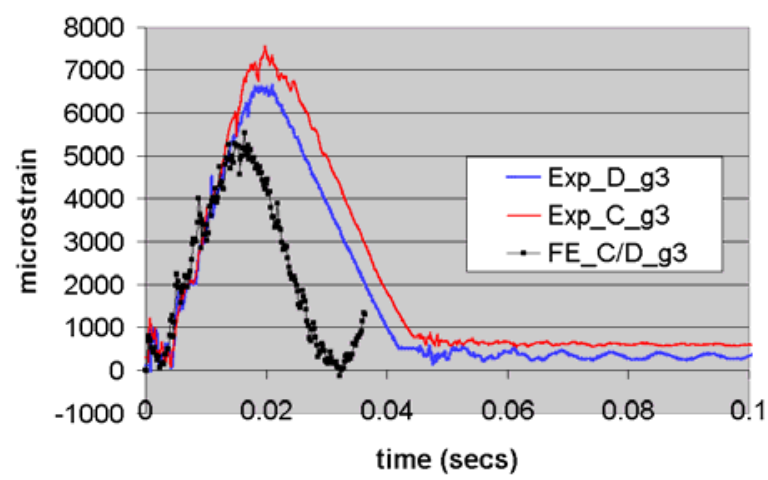

(a)

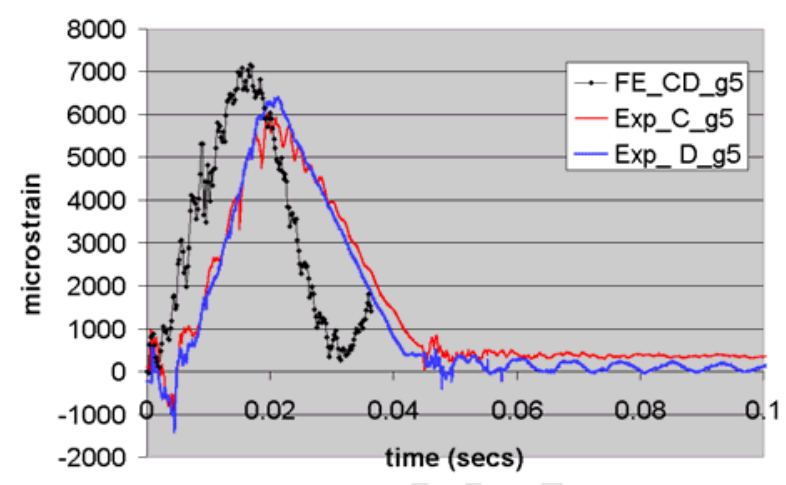

(b)

Figure 19. Strain predictions for gauges located on plate large1(D), a distance from the plate centre of (a) $\sim 100 \mathrm{~mm}$ longitudinally, impact face (b) $190 \mathrm{~mm}$ widthwise, under-side

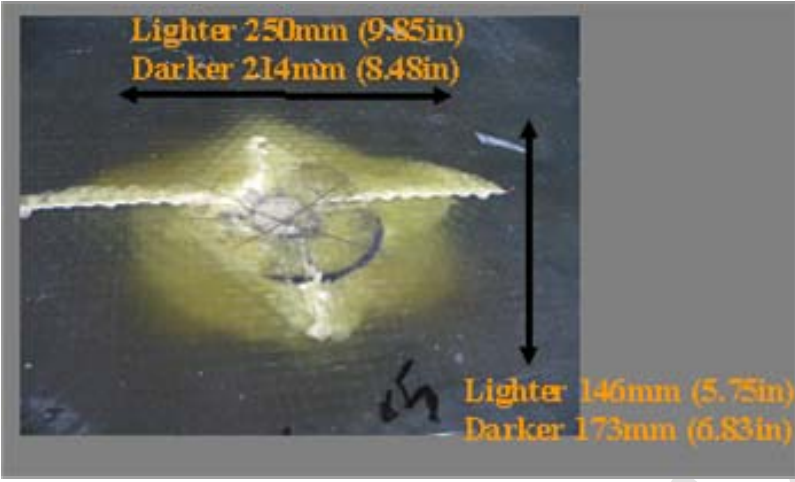

Figure 20. Damage viewed from the top face, large1(D)

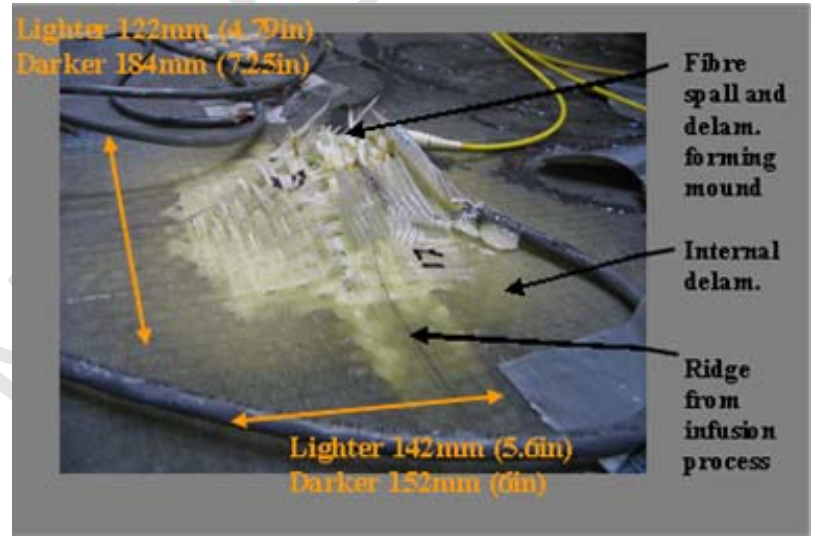

Figure 21.Damage viewed from the bottom face, large1(D), showing one of the underside gauges (labeled 17)

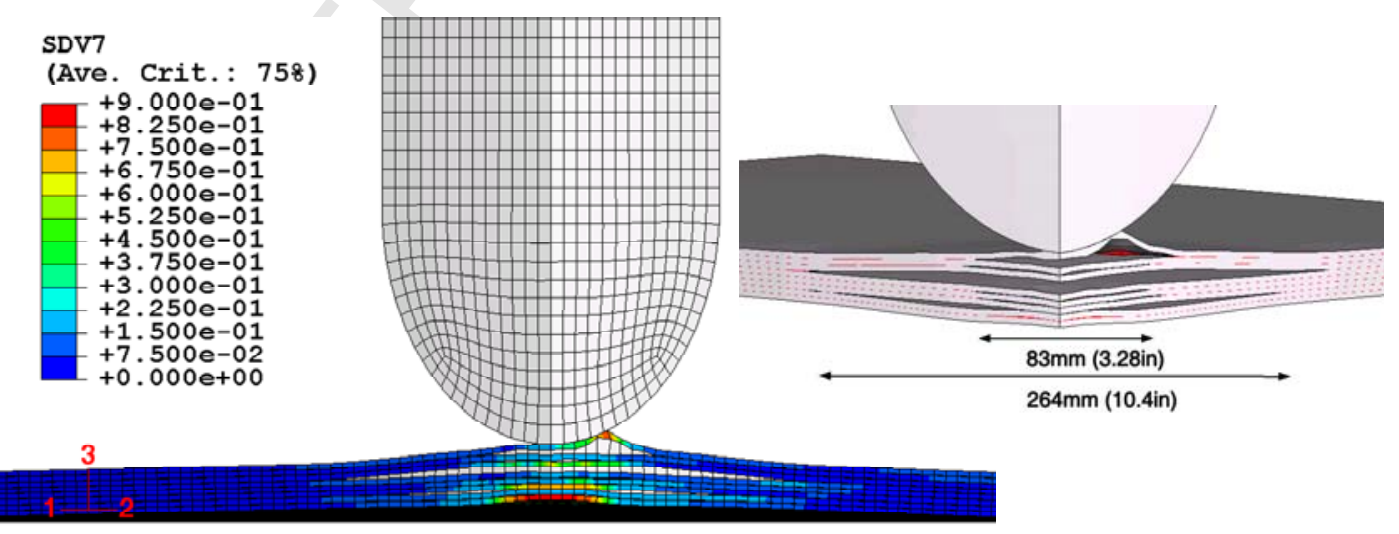

Figure 22. $d_{1}$ contours for test large1(C/D) highlighting the delamination damage 


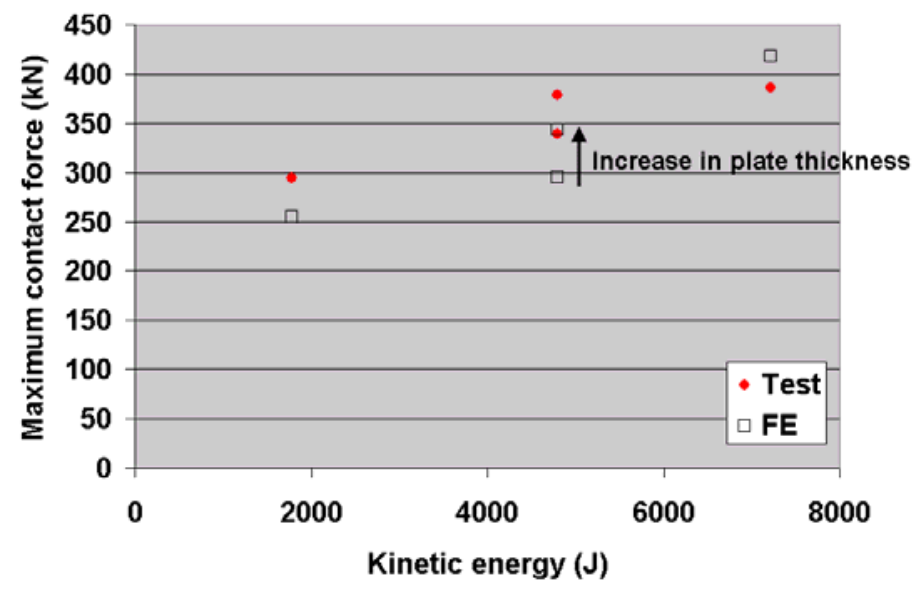

Figure 23. Contact force-incident kinetic energy for large plates - test versus FE

\begin{tabular}{|c|c|c|c|c|c|c|c|c|c|}
\hline$E_{11 T}$ & $E_{11 C}$ & $E_{22 T}$ & $\mathrm{E}_{11 \mathrm{C}}$ & $E_{12}$ & $E_{13}$ & $E_{23}$ & $\mathrm{E}_{33 \mathrm{~T}}$ & $E_{33 \mathrm{C}}$ & $\mathrm{v}_{12}$ \\
\hline 24.139 & 23.37 & 24.139 & 23.37 & 8.273 & 3.586 & 3.586 & $\begin{array}{c}16.89 \\
\text { (range } \\
6.18 \text { to } \\
22.7 \text { ) }\end{array}$ & $\begin{array}{c}8.1 \\
\text { (range } \\
6.18 \text { to } \\
9.38 \text { ) }\end{array}$ & 0.14 \\
\hline
\end{tabular}

Table 1. Material properties for the WR E-glass/Derakane 8084 vinyl-ester, moduli in GPa.

\begin{tabular}{|c|c|c|c|c|c|c|}
\hline $\mathrm{S} 11_{\mathrm{T}}$ (warp) & $\mathrm{S} 22_{\mathrm{T}}$ (weft) & $\mathrm{S} 11_{\mathrm{c}}=\mathrm{S} 22_{\mathrm{c}}$ & $\mathrm{S} 13$ & $\mathrm{~S} 23$ & $\mathrm{~S} 33_{\mathrm{T}}$ & $\mathrm{S}_{3} 3_{\mathrm{C}}$ \\
\hline 330.328 & 298.6 & 329.6 & 51.6 & 51.6 & $\begin{array}{c}30.5 \\
\text { (range 19.37 } \\
\text { to 41.71) }\end{array}$ & $\begin{array}{c}570 \\
\text { (range 520 } \\
\text { to 620) }\end{array}$ \\
\hline
\end{tabular}

Table 2. Average material properties for the WR E-glass/Derakane 8084 vinyl-ester in tension ' $\mathrm{T}$ ' and compression ' $\mathrm{C}$ ', in $\mathrm{MPa}$

\begin{tabular}{|c|c|c|c|}
\hline Test tag name & Plate dimensions $/ \mathrm{m}$ & Tup mass $/$ dimension & Test Ref.s \\
\hline Small & $0.2286 \times 0.1778 \times 0.00635$ & $12.7 \mathrm{~mm} / 25.4 \mathrm{~mm} / 38 \mathrm{~mm}$ & - \\
\hline Large1 & $1.07315 \times 0.76835 \times 0.019$ & $340 \mathrm{~kg} / 455 \mathrm{~kg} / 682 \mathrm{~kg}$ & $\mathrm{~A} / \mathrm{B} / \mathrm{C}, \mathrm{D}$ \\
\hline Large2(1) & $1.37 \times 1.37 \times 0.038$ & $340 \mathrm{~kg} / 455 \mathrm{~kg} / 682 \mathrm{~kg}$ & $\mathrm{~A} / \mathrm{B} / \mathrm{C}, \mathrm{D}$ \\
\hline Large2(2) & $1.37 \times 1.37 \times 0.038$ & $340 \mathrm{~kg} / 455 \mathrm{~kg} / 682 \mathrm{~kg}$ & $\mathrm{~A} / \mathrm{B} / \mathrm{C}, \mathrm{D}$ \\
\hline
\end{tabular}

Table 3. The summary of experimental specimens along with tup masses/dimensions 


\begin{tabular}{|l|l|l|l|}
\hline Cyclic testing & $\boldsymbol{\varepsilon}_{\mathbf{f}}$ & $\boldsymbol{\varepsilon}_{\max }$ & $\mathbf{d}_{\text {II }}$ \\
\hline Warp, tensile & 0.0225 & 0.04 (Williams et al.) & 0.17 \\
\hline Warp, compressive & -0.015 & -0.04 & 0.035 \\
\hline Weft, tensile & 0.0208 & 0.04 & 0.23 \\
\hline Weft, compressive & -0.015 & -0.04 & 0.027 \\
\hline
\end{tabular}

Table 4. Average damage propagation parameters.

\begin{tabular}{|c|c|c|c|c|c|c|c|}
\hline Test & $\begin{array}{c}\text { Tup velocity / } \\
\mathrm{ms}^{-1}\end{array}$ & $\begin{array}{c}\text { Mass/ } \\
\mathrm{kg}\end{array}$ & $\begin{array}{l}\text { Contact } \\
\text { Force/ } \\
\mathrm{kN}\end{array}$ & $\begin{array}{c}\text { Midpoint } \\
\text { displacement } \delta / \\
\mathrm{m} \\
{[\mathrm{FE} \text { in } \mathrm{m}]}\end{array}$ & $\begin{array}{l}\text { Test, damage size } \\
\text { (Top) } / \mathrm{m} \\
{[\mathrm{FE} \text { in } \mathrm{m}](\text { cohesive }} \\
\text { layer)* }\end{array}$ & $\begin{array}{c}\text { Test, damage size } \\
\text { (Bottom) } / \mathrm{m} \\
{[\mathrm{FE} \text { in } \mathrm{m}] \text { (cohesive layer)* }}\end{array}$ & $\begin{array}{c}\text { Energy } \\
\text { Level } \\
\text { / J }\end{array}$ \\
\hline 1 & 4.59 & 8.55 & 15.15 & 0.0119 & $\begin{array}{l}0.0381 \times 0.0254 \\
{[0.0253 \times 0.016]}\end{array}$ & $\begin{array}{l}0.0381 \times 0.0381 \\
{[0.0253 \times 0.022]}\end{array}$ & 91.52 \\
\hline 2 & 4.572 & 13.33 & 20.35 & $\begin{array}{c}0.0141 \\
{[0.016]}\end{array}$ & $\begin{array}{c}0.03175 \times 0.0254 \\
{[0.0492 \times 0.035](\mathrm{c} 1)}\end{array}$ & $\begin{array}{c}0.0381 \times 0.0381 \\
{[0.0318 \times 0.0286](\mathrm{c} 8)}\end{array}$ & 140.57 \\
\hline \multirow[t]{2}{*}{3} & \multirow[t]{2}{*}{4.581} & \multirow[t]{2}{*}{15.87} & \multirow[t]{2}{*}{20.77} & $\begin{array}{l}0.0158 \\
{[0.015]}\end{array}$ & $\begin{array}{c}0.0381 \times 0.0254 \\
{[0.0492 \times 0.0438](\mathrm{c} 6,8)}\end{array}$ & $\begin{array}{c}0.0381 \times 0.0508 \\
{[0.0552 \times 0.0492](\mathrm{c} 1,2)} \\
\end{array}$ & \multirow[t]{2}{*}{165.82} \\
\hline & & & & (Partial Penetration) & $\begin{array}{c}0.03175 \times 0.0254 \\
{[0.0492 \times 0.035](\mathrm{c} 7,8)}\end{array}$ & $\begin{array}{c}0.0381 \times 0.0381 \\
{[0.0192 \times 0.0192](\mathrm{c} 1-3)}\end{array}$ & \\
\hline $4^{+}$ & 4.584 & 18.37 & 17.73 & Penetration & $\begin{array}{c}0.03175 \times 0.0254 \\
{[0.0436 \times 0.022](\mathrm{c} 8)}\end{array}$ & $\begin{array}{c}0.0381 \times 0.0381 \\
{[0.022 \times 0.0436](\mathrm{c} 1,2)} \\
\end{array}$ & 193 \\
\hline 5 & 4.615 & 18.37 & 22.52 & Penetration & $\begin{array}{c}0.0381 \times 0.0254 \\
{[0.0492 \times 0.035](\mathrm{c} 8)}\end{array}$ & $\begin{array}{c}0.0381 \times 0.0381 \\
{[0.0318 \times 0.0318)(\mathrm{c} 1,2)}\end{array}$ & 195.6 \\
\hline 6 & 4.594 & 18.62 & 26.98 & Penetration & & & 196 \\
\hline
\end{tabular}

Table 5. Small tup ' $\mathrm{S}$ ' (12.7mm dia.) - small plate test results and FE delamination predictions, using a co8_p2t2 mesh. ' $c 1$ ' is the cohesive layer nearest the bottom of the plate and ' $c 8$ ' is nearest the top.

\begin{tabular}{|c|c|c|c|c|c|c|c|}
\hline Test & $\begin{array}{c}\text { Tup velocity } \\
\mathrm{ms}^{-1}\end{array}$ & $\begin{array}{c}\text { Mass/ } \\
\mathrm{kg}\end{array}$ & $\begin{array}{c}\text { Contact } \\
\text { Force/ } \\
\mathrm{kN}\end{array}$ & $\begin{array}{c}\text { Midpoint } \\
\text { displacement } \delta / \\
\mathrm{m} \\
{[\text { FE in } \mathrm{m}]}\end{array}$ & $\begin{array}{c}\text { Test, damage size } \\
(\text { Top) } / \mathrm{m} \\
{[\text { FE in } \mathrm{m}](\text { cohesive }} \\
\text { layer)* }\end{array}$ & $\begin{array}{c}\text { Test, damage size } \\
\text { (Bottom) } / \mathrm{m} \\
\text { (cohesive layer) }\end{array}$ & $\begin{array}{c}\text { Energy } \\
\text { Level } \\
/ \mathrm{J}\end{array}$ \\
\hline 9 & 4.593 & 18.70 & 24.93 & $\begin{array}{c}0.0159 \\
{[0.017]}\end{array}$ & $\begin{array}{c}0.03175 \times 0.0254 \\
{[0.044 \times 0.044](\mathrm{c} 5)}\end{array}$ & $\begin{array}{c}0.0381 \times 0.03175 \\
{[0.038 \times 0.038](\mathrm{c} 3)}\end{array}$ & 195.51 \\
\hline 10 & 4.596 & 20.34 & 27.86 & $\begin{array}{c}0.0165 \\
{[0.018]}\end{array}$ & $\begin{array}{c}0.0381 \times 0.03175 \\
{[0.052 \times 0.038](\mathrm{c} 7)}\end{array}$ & $\begin{array}{c}0.0381 \times 0.03175 \\
{[0.043 \times 0.033](\mathrm{c} 4)}\end{array}$ & 217.41 \\
\hline $7 \_\mathrm{R}$ & 4.596 & 23.69 & 27.74 & $\begin{array}{c}0.0186 \\
\text { iPartial Penetration) } \\
{[0.019]}\end{array}$ & $\begin{array}{c}0.03175 \times 0.0381 \\
{[0.0478 \times 0.043](\mathrm{c} 7)}\end{array}$ & $\begin{array}{c}0.04445 \times 0.04445 \\
{[0.0382 \times 0.033](\mathrm{c} 2 \& 4)}\end{array}$ & 247.59 \\
\hline
\end{tabular}

Table 6. Medium tup ' $\mathrm{M}$ ' (25.4mm dia.) - small plate test results and FE delamination predictions, using a co8_p2t2 mesh. 'c1' is the cohesive layer nearest the bottom of the plate and 'c8' is nearest the top. 


\begin{tabular}{|c|c|c|c|c|c|c|c|}
\hline Test & $\begin{array}{c}\text { Tup velocity } \\
/ \\
\text { ms-1 }\end{array}$ & $\begin{array}{c}\text { Mass/ } \\
\mathrm{kg}\end{array}$ & $\begin{array}{c}\text { Contact } \\
\text { Force/ } \\
\text { kN }\end{array}$ & $\begin{array}{c}\text { Midpoint } \\
\text { displacement } \delta \\
/ \\
\mathrm{m} \\
{[\mathrm{FE} \text { in } \mathrm{mm}]} \\
\end{array}$ & $\begin{array}{l}\text { Test, damage size } \\
\text { (Top) } / \mathrm{m} \\
{[\mathrm{FE} \text { in } \mathrm{m}](\text { cohesive }} \\
\text { layer)* }\end{array}$ & $\begin{array}{l}\text { Test, damage size } \\
\text { (Bottom) } / \mathrm{m} \\
{[\mathrm{FE} \text { in } \mathrm{m}] \text { (cohesive }} \\
\text { layer)* }\end{array}$ & $\begin{array}{l}\text { Energy } \\
\text { Level } \\
\text { / J }\end{array}$ \\
\hline $\begin{array}{c}11 \\
(281)\end{array}$ & 4.60553 & 20.26 & 22.28 & $\begin{array}{l}0.0206 \\
{[0.019]}\end{array}$ & $\begin{array}{l}0.04445 \times 0.0381 \\
{[0.073 \times 0.036](\mathrm{c} 8)}\end{array}$ & $\begin{array}{c}0.0381 \times 0.0381 \\
{[0.0437 \times 0.0382](\mathrm{c} 1)}\end{array}$ & 211.71 \\
\hline $\begin{array}{c}12 \\
(282) \\
\end{array}$ & 4.60553 & 24.32 & 23.43 & $\begin{array}{l}0.0223 \\
{[0.025]}\end{array}$ & $0.04445 \times 0.0381$ & $0.0381 \times 0.0381$ & 263.41 \\
\hline $\begin{array}{c}13 \\
(283)\end{array}$ & 4.60858 & 26.19 & 24.86 & $\begin{array}{r}0.0229 \\
{[0.02]}\end{array}$ & $\begin{array}{c}0.05715 \times 0.03175 \\
{[0.055 \times 0.029](\mathrm{c} 7,8)}\end{array}$ & $\begin{array}{c}0.0381 \times 0.0381 \\
{[0.0318 \times 0.035](\mathrm{c} 1-2)}\end{array}$ & 284.05 \\
\hline $\begin{array}{c}14 \\
(284)\end{array}$ & 4.69087 & 26.19 & 24.57 & $\begin{array}{l}0.0236 \\
{[0.028]}\end{array}$ & $\begin{array}{c}0.0381 \times 0.0381 \\
{[0.068 \times 0.036](\mathrm{c} 6-8)}\end{array}$ & $\begin{array}{c}0.04445 \times 0.0381 \\
{[0.055 \times 0.0494](\mathrm{c} 1,2)}\end{array}$ & 294.16 \\
\hline $\begin{array}{c}15 \\
(285)\end{array}$ & 6.2088 & 26.19 & 28.13 & $\begin{array}{l}0.0376 \\
{[0.024]}\end{array}$ & $\begin{array}{c}0.03175 \times 0.03175 \\
{[0.0976 \times 0.1778](\mathrm{c} 8)}\end{array}$ & $\begin{array}{c}0.05715 \times 0.04445 \\
{\left[0.072 \times 0.1778^{* *}\right](\mathrm{c} 1)}\end{array}$ & 495.85 \\
\hline $\begin{array}{c}16 \\
(286) \\
\end{array}$ & 7.13 & 26.19 & 29.40 & $\begin{array}{l}0.0546 \\
{[0.03]}\end{array}$ & $\begin{array}{c}0.06985 \times 0.0508 \\
{[0.055 \times 0.0318](\mathrm{c} 6-8)}\end{array}$ & $\begin{array}{c}0.03175 \times 0.03175 \\
{[0.0794 \times 0.0492](\mathrm{c} 1)}\end{array}$ & 664.9325 \\
\hline
\end{tabular}

Table 7. Small plate, large tup ' $\mathrm{L}$ ' (38.1 mm dia.) test results and FE delamination predictions, using a co 8 p $2 \mathrm{t} 2$ mesh. ' $c 1$ ' is the cohesive layer nearest the bottom of the plate and ' $\mathrm{c} 8$ ' is nearest the top.

\section{Reference List}

(1) Zhou G., Greaves L.J.: Damage resistance and tolerance of thick laminated woven roving GFRP plates subjected to low-velocity impact; in: Reid SR, Zhou G, (eds): Impact Behaviour of Fibre-reinforced Composite Materials and Structures. Woodhead Publishing Ltd, 2000, pp 133-183.

(2) Iannucci L., Willows M.L.: An energy based damage mechanics approach to modelling impact onto woven composite materials - Part I: Numerical models. Composites Part A-Applied Science and Manufacturing 2006; 37(11):2041-2056.

(3) Van Paepegem W., Degrieck J.: A new coupled approach of residual stiffness and strength for fatigue of fibre-reinforced composites. International Journal of Fatigue 2002; 24:747-762.

(4) Ladeveze P, LeDantec E: Damage modelling of the elementary ply for laminated composites. Composites Science and Technology 1992; 43(3):257-267.

(5) Chaboche JL: Continuum Damage Mechanics. I. General Concepts. Journal of applied mechanics 1988; 55:59-64.

(6) Iannucci L., Dechaene R., Willows M., Degrieck J.: A failure model for the analysis of thin woven glass composite structures under impact loadings. Computers \& Structures 2001; 79(8):785-799.

(7) Camanho PP, Davila CG. Mixed-Mode Decohesion Finite Elements for the Simulation of Delamination in Composite Materials. NASA/TM-2002-211737. 2002. NASA. Ref Type: Report

(8) Matzenmiller A., Lubliner J., Taylor R.L.: A constitutive model for anisotropic damage in fibercomposites. Mechanics of Materials 1995; 20(2):125-152.

(9) Kollegal M: Progressive failure analysis of plain weaves using damage mechanics based constitutive laws. International journal of damage mechanics 2001; 10(4):301-323.

(10) Elder D.J., Thomson R.S., Nguyen MQ, Scott M.L.: Review of delamination predictive methods for low speed impact of composite laminates. Composite Structures 2004; 66(1-4):677-683. 
(11) Boh J.W., Louca L.A., Choo Y.S., Mouring S.E.: Damage modelling of SCRIMP woven roving laminated beams subjected to transverse shear. Composites Part B: Engineering 2005; 36(5):427-438.

(12) Johnson H.E., Louca L.A., Mouring S.E.: Current research into modelling of shock damage to large scale composite panels. Journal of Materials Science, Special Edition 2006; 41(20):6655-6672.

(13) Espinosa HD, Dwivedi S, Lu H-C: Modelling impact induced delamination of woven fiber reinforced composites with contact/cohesive laws. Computer Methods in Applied Mechanics and Engineering 2000; 183(3-4):259-290.

(14) Scheider I. Cohesive Model for Crack Propagation Analyses of Structures with Elastic-Plastic Material Behavior: Foundations and Implementation. 2001. GKSS Research Center, Geesthacht, Dept. WMS. Ref Type: Report

(15) Camanho PP, Davila CG, Pinho ST: Fracture analysis of composite co-cured structural joints using decohesion elements. Fatigue \& Fracture of Engineering Materials \& Structures 2004; 27(9):745-757.

(16) Turon A, Davila CG, Camanho PP, Costa J. An engineering solution for using coarse meshes in the simulation of delamination with cohesive zone models. NASA/TM-2005-213547. 2005. NASA. Ref Type: Report

(17) Lemmen P., Meijer G.-J., and Rasmussen E.A. Dynamic behavior of composite ship structures (DYCOSS) failure prediction tool. 2006. Ref Type: Unpublished Work

(18) Hashin Z.: Failure criteria for unidirectional fiber composites. Journal of applied mechanics 1980; 47(2):329-334.

(19) Sierakowski R.L., Chaturverdi S.K.: Impact Damage Modelling; Dynamic Loading and Characterization of fiber-reinforced composites. New York; Chichester : Wiley, 1997, p 215.

(20) Davies G.A.O., Hitchings D., Zhou G.: Impact damage and residual strengths of woven fabric glass/polyester laminates. Composites Part A: Applied Science and Manufacturing 1996; 27(12):11471156.

(21) Sutherland L.S., Guedes Soares C.: Impact characterisation of low fibre-volume glass reinforced polyester circular laminated plates. International Journal of Impact Engineering 2005; 31(1):1-23.

(22) Smith CS, Murphy P: Response of hybrid GRP/steel superstructures to blast loading - Theory and Experiment; Advances in Marine Structures. Elsevier Applied Science, 1991.

(23) Heimbs S, Schmeer S, Middendorf P, Maier M: Strain rate effects in phenolic composites and phenolicimpregnated honeycomb structures. Composites Science and Technology 2007; 67(13): 2827-2837

(24) Dechaene R: A constitutive model for glass fibre fabric composites under impact. Journal of Composite Materials 2002; 36(8):983-1004.

(25) Mouritz AP, Gallagher J, Goodwin AA: Flexural strength and interlaminar shear strength of stitched GRP laminates following repeated impacts. Composites Science and Technology 1997; 57(5):509-522.

(26) Talreja R.: Transverse cracking and stiffness reduction in composite laminates. Journal of Composite Materials 1985; 19:355-375.

(27) Wharmby AW, Ellyin F, Wolodko JD: Observations on damage development in fibre reinforced polymer laminates under cyclic loading. International Journal of Fatigue 2003; 25(5):437-446. 
(28) Asp LE, Berglund LA, Talreja R: Prediction of matrix-initiated transverse failure in polymer composites. Composites Science and Technology 1996; 56(9):1089-1097.

(29) Williams K.V., Vaziri R., Poursartip A.: A physically based continuum damage mechanics model for thin laminated composite structures. International Journal of Solids and Structures 2003; 40(9):2267-2300.

(30) Brewer JC, Legace PA: Quadratic stress criterion for initiation of delamination. Journal of Composite Materials 1988; 22(12):1141-1155.

(31) Boh J.W., Louca L.A., Choo Y.S., Mouring S.E.: Damage modelling of SCRIMP woven roving laminated beams subjected to transverse shear. Composites Part B: Engineering 2005; 36(5):427-438.

(32) Kongshavn I, Poursartip A: Experimental investigation of a strain-softening approach to predicting failure in notched fibre-reinforced composite laminates. Composites Science and Technology 1999; 59(1):29-40.

(33) Zako M, Uetsuji Y, Kurashiki T: Finite element analysis of damaged woven fabric composite materials. Composites Science and Technology 2003; 63(3-4):507-516.

(34) Alif N, Carlsson LA, Boogh L: The effect of weave pattern and crack propagation direction on mode I delamination resistance of woven glass and carbon composites. Composites Part B-Engineering 1998; 29(5):603-611.

(35) Sihn S, Iarve EV, Roy AK: Three-dimensional stress analysis of textile composites: Part I. Numerical analysis. International Journal of Solids and Structures 2004; 41(5-6):1377-1393.

(36) Siron O, Pailhes J, Lamon J: Modelling of the stress/strain behaviour of a carbon/carbon composite with a 2.5 dimensional fibre architecture under tensile and shear loads at room temperature. Composites Science and Technology 1999; 59(1):1-12.

(37) Goyal V.K., Johnson E.R., Davila CG, Jaunky N. An irreversible constitutive law for modelling the delamination process using interface elements. NASA/CR-2002-211758, ICASE Report No. 2002-25. 2002. NASA. Ref Type: Report

(38) Mamalis A.G., Manolakos D.E., Ioannidis M.B., Papapostolou D.P. Crashworthy characteristics of axially statically compressed thin-walled square CFRP composite tubes: experimental Composite Structures 2004; 63(3): $347-360$

(39) Wang W., Makarov G. , Shenoi R.A. An analytical model for assessing strain rate sensitivity of unidirectional composite laminates, Composite Structures 2005; 69(1): 45-54

(40) Zhu L., Chattopadhyay A., Goldberg R.K. Nonlinear transient response of strain rate dependent composite laminated plates using multiscale simulation. International Journal of Solids and Structures 2006; 43(9): $2602-2630$

(41) Xia Y., Yuan J., Yang B. A statistical models and experimental study of the strain-rate dependence of the strength of fibres. Composite Science and Technology 1994; 52: 499-504

(42) Shah Khan M.Z., Simpson G., Gellert E. P. Resistance of glass-fibre reinforced polymer composites to increasing compressive strain rates and loading rates Composites Part A: Applied Science and Manufacturing, 2000;31(1), 57-67

(43) Ochola R.O., Marcus K., Nurick G.N. and Franz T. Mechanical behaviour of glass and carbon fibre reinforced composites at varying strain rates Composite Structures 2004;63(3-4), 455-467 
(44) Iannucci L. Ankersen J. An energy based damage model for thin laminated composites Composites Science and Technology 2006; 66(7-8), 934-951

(45) Hillerborg A, Modéer M. \& Petersson P.E. Analysis of Crack Formation and Crack Growth in Concrete by Means of Fracture Mechanics and Finite Elements. Cement and Concrete Research 1976; 6: 773-782

(46) Turon A., Davila C.G, Camanho P P, Costa J. An Engineering Solution for using Coarse Meshes in the Simulation of Delamination With Cohesive Zone Models. NASA/TM-2005-213547. 2005. NASA. Ref Type: Report

(47) Mouritz AP, Saunders DS, Buckley S: The damage and failure of GRP laminates by underwater explosion shock loading. Composites 1994; 25(6):431-437.

(48) Mouritz A.P.: The damage to stitched GRP laminates by underwater explosion shock loading. Composites Science and Technology 1995; 55(4):365-374. 